\title{
Spectroscopy techniques and the measurement of molecular radical densities in atmospheric pressure plasmas
}

\author{
Robert Peverall and Grant A.D. Ritchie \\ Department of Chemistry, Physical and Theoretical Chemistry Laboratory, The University of \\ Oxford, South Parks Road, Oxford, OX1 3QZ
}

\begin{abstract}
Cold atmospheric pressure plasmas (CAPs) are finding an increasing number of applications in diverse fields such as sterilization, medicine and dentistry, because they induce chemical reactivity at nearambient temperature. These plasmas are usually generated in noble gas flows which propagate into air, resulting in the production of a wide variety of species which can cause primary and secondary chemistry in both the gas and liquid phases. Detailed understanding of this low temperature reactivity requires selective and sensitive measurements of radical species. In this review we focus upon several techniques from a methodological point of view that are suitable for the sensitive detection of reactive species, or show promise for this purpose. A range of traditional and contemporary spectroscopic methods for measuring across different phases is highlighted in an attempt to present a 'detection landscape' for CAP-borne radicals.
\end{abstract}




\section{Introduction}

Developed over the last couple of decades, cold atmospheric pressure plasmas (CAPs) come in various guises ${ }^{1-14}$ and have found application in many fields, from dental hygien $e^{15-19}$ to surface treatment and modification $^{20-27}$. Related areas where these devices seem to show great promise are in plasma medicine and decontamination ${ }^{16,28-51}$, but while discoveries of practical applications of CAPs have progressed rapidly, our detailed scientific understanding of these devices has advanced at a slower pace. The reasons for this are many fold; for one, these discharges are small, usually on a $\mathrm{mm}$ scale and thus investigative techniques that rely on sample size become less effective. Clearly, another problem has been not only the variety of possible geometries that these devices can take (including how they are driven), but also their reproducibility and how susceptible they are to both intrinsic and extrinsic factors and perturbations. Great care must therefore be taken in designing experiments that will truly yield useful information both on the function of the plasma and the device. In most practical applications the plasma will interact with a surface or liquid, and in such situations key properties can be influenced greatly by the heterogeneous nature of the plasma - target interaction. In order to fully understand such systems, measurements in the gas and liquid phases and/or on surfaces/interfaces are required.

CAPs tend to be operated predominantly with a noble gas in an air environment and are therefore a rich source of reactive oxygen and nitrogen species (RONS $)^{39,52-61}$ such as $\mathrm{OH}, \mathrm{HO}_{2}, \mathrm{O}\left({ }^{3} \mathrm{P}\right)$, $\mathrm{NO}_{2}, \mathrm{NO}, \mathrm{O}_{3}, \mathrm{O}_{2}\left(\mathrm{a}^{1} \Delta_{\mathrm{g}}\right)$, and peroxynitrous acid, $\mathrm{ONOOH}$. Many of these atomic and molecular species have one or more unpaired electrons, and they play a key role in the ensuing plasma (induced) chemistry and much has been done to try to understand this low temperature oxidizing environment. Taking the increasing number of medical applications as an exemplar, where plasma has been shown to impact upon such things as tumour development, blood coagulation and wound healing (e.g. 1,33,37$39,41-43,45,46,48,49,51,57,62-71)$, then clearly the interaction of the plasma and RONS with tissue and bio-liquids, at the interface region and within the liquid, is important. It is currently assumed that the underlying mechanisms by which plasma influences biological activity are defined by the way in which plasmagenerated RONS interact with the components of biological liquid, cells and tissue, and it has been suggested that plasma-generated RONS are capable of stimulating cellular signalling mechanisms that trigger cell death and that these signals can be transmitted deeper into tissue through cell-to-cell communication, in a manner similar to that seen in other forms of cell stress. ${ }^{72-74}$ However, while the reasoning behind such ideas is rational, there is a lack of quantitative information to back this up that persists for all phases of the plasma - surface - liquid system. Indeed, even for the gas phase where RONS are initially produced, only a limited number of quantitative measurements on the number densities of these radical species have been reported.

With few exceptions radical species readily react and consequently have short lifetimes within CAPs. Radicals are often present only in trace amounts, making their quantification difficult. Despite their small (apparent) concentration, they are however the driving force behind much of the chemistry, and are vital species that need to be measured in order to fully understand the chemistry both within, and induced by, the CAP. Furthermore, in many CAP configurations the excitation is transient, sometimes lasting only a few ns, and so the fast timescale temporal evolution of radical species is also important.

In this review we seek to give an overview of recent developments in the interrogation of CAPs, purely from a methodological point of view, focusing upon techniques that either have been shown to be suitable for the sensitive detection of radical or reactive species, or show promise for this 
purpose. Techniques pertinent to making measurements across different phases are also described and an attempt is made to present the 'detection landscape' for reactive species in CAPs. This is not intended as a comprehensive guide, as numerous good review articles already exist on many of the topics (as referenced where relevant in this manuscript), but is intended to give a flavour of established methodologies and to give some context to methods described here.

\section{Determination of radical densities in the gas phase}

A mainstay of diagnostics for plasma systems, optical emission spectroscopy (OES) has long been a go-to technique to obtain basic information about a discharge. We choose not to include it in this review, as much has previously been written on the subject; suffice to say that OES is only sensitive to internally excited species (generally in the form of electronic excitation), it is difficult to quantify, and can never tell the observer definitively about the absence of a particular species. However, we note that in the field of atmospheric plasmas researchers have found spectrally-resolved ns timescale imaging to be particularly useful, elucidating spatial phenomena associated with CAPs, including bullet - like streamer propagation, discharge annularity and the existence and evolution of energisation within the plasma. ${ }^{75-84}$

Laser induced fluorescence (LIF) is a well-established method for measuring radical number densities and is used in atmospheric science for the detection of species such as $\mathrm{OH}^{85}$ and NO. Notably, the radicals are drawn from the ambient atmosphere into a detection chamber which is at lower pressure so that collisional quenching of the fluorescing electronically excited state is minimised. LIF has also shown great utility in plasma diagnostics ${ }^{86-115}$, but signal retrieval and analysis is complex, predominantly because of the large potential background. While this issue can be alleviated using schemes which include devices such as gated photomultipliers and by probing the discharge postexcitation, extraction of quantitative information is still difficult. One particular problem is the influence that energy transfer and quenching have on the excited state used in the LIF scheme, which are particularly challenging to overcome in atmospheric plasma systems. Nevertheless, LIF offers sensitive quantum state resolved information with very high spatial $(<100 \mu \mathrm{m})$ and temporal $(<\mathrm{ns})$ resolution, and if calibrated carefully can yield reliable results. Here we refer the reader to the comprehensive article by Dilecce et al. ${ }^{108}$ for further details on the use of LIF for atmospheric pressure plasma systems. Optical-optical double resonance LIF (OODR-LIF) and two-photon LIF ${ }^{116-119}$ are associated techniques where the upper state in the excitation scheme is accessed either via an intermediate resonant state or by non-resonant two-photon absorption. Both could be a judicious choice if either the required excited state lies at a high energy (compared to the energy of UV photons which are readily available from frequency up-conversion with pulsed lasers), or if by using a two photon transition a state can be accessed that is not heavily populated by direct electron impact from the ground state, as could be the case for a state with strong optical coupling to the ground state. Two-photon-absorption LIF or TALIF is such a two photon technique which, in plasma diagnostics, has been used almost exclusively for the detection of atomic species.

TALIF $^{120,121}$ has become ubiquitous for measuring the atomic species $\mathrm{O}, \mathrm{H}, \mathrm{N}$ and typical schemes for the measurement of these species are shown in figure 1. Generally, TALIF offers unrivalled spatiotemporal sensitivity for plasma measurements $(<100 \mu \mathrm{m}$; ns, i.e. similar to LIF), is formally a background free technique, and well suited for CAP analysis. Recently, TALIF has been extended into the fs laser pump regime ${ }^{122,123}$ where there are potential benefits for some applications. This has been 
demonstrated in an oxygen containing plasma, where due to the natural large linewidth of the laser $(\sim 1 \mathrm{~nm})$, all three spin-orbit states of $\mathrm{O}\left({ }^{3} \mathrm{P}_{2,1,0}\right)$ were excited simultaneously. In addition, a fs system has the inherent ability to measure accurately sub-ns excited state decay times which can be observed in a high quenching regime, such as where a plasma plume interacts and mixes with air. Accurate lifetime measurements are intrinsic to the quantification of data using TALIF. Indeed, without the utility of a ps or fs laser, great care is needed in order to extract quantitative information using this technique, especially at atmospheric pressure, where quenching plays a dominant role in the lifetime of the excited state(s) and that of the calibrant required for comparison (usually Xe in the case of $\mathrm{O}\left({ }^{3} \mathrm{P}\right.$ ) measurements). Assumptions will always be necessary about the quenching species, due to the variable nature of a plasma which contains potentially high levels of metastable species (e.g. $\left.\mathrm{O}_{2}\left(a^{1} \Delta_{\mathrm{g}}\right)\right)$, dissociation products and ions, and electronic ground state species whose internal energy distributions $(X(v, J))$ are not thermalised. Also, it is essential that the laser fluence is maintained at (low) levels such that the two-photon excitation rate is proportional to the square of the laser intensity so as not to induce further excitation or ionisation from the excited state. Other related techniques that have been utilised for measurements of molecular species in flames and combustion include Degenerate Four Wave Mixing (DFWM) and polarisation spectroscopy, ${ }^{124,125}$ but these have not (yet) found widespread use in studies on CAPs. DFWM has yielded effective single shot $\mathrm{OH}$ temperature measurements in a sheet configuration. ${ }^{126}$ However, it is very difficult to extract absolute concentrations from these techniques. An excellent summary is given in Kiefer and Ewart ${ }^{124}$ including the pitfalls and difficulties in extracting quantitative information. Associated non-resonant methods such as Raman spectroscopy and Coherent Anti-Stokes Raman spectroscopy (CARS) are unsuitable for radical measurements because of low sensitivity, although have been used to measure vibrationally excited states of $\mathrm{N}_{2} \cdot{ }^{127,128}$ Recently however, even these techniques have been extended with 'resonant variants' and ultrafast capability (i.e. with ps or fs laser sources) and have been shown suitable for the detection of minor species $(\mathrm{OH} \text { and } \mathrm{NO})^{129,130}$. A recent review covers this material comprehensively including a perspective on the future opportunities for flame and plasma diagnostics using ultrafast sources. ${ }^{130}$

Many radical species in the plasma environment are accessible to straightforward optical absorption techniques and have been measured in CAP systems using laser absorption spectroscopy, or UV/VUV spectroscopy with broadband light sources. Much has already been written on the absorption of plasma borne species including several seminal reviews (see following text), and so we limit our approach here to a quick resume of a few target specific techniques pertinent to radical species.

Traditional absorption spectroscopy has been widely used for probing excited state atomic species in CAPs, and a great deal has been learnt from these studies. Metastable atomic species such as $\operatorname{Ar}\left(1 s_{3}, 1 s_{5}\right.$ levels derived from the $3 p^{5} 4 s^{1}$ configuration) and $\mathrm{He}\left({ }^{1} \mathrm{~S},{ }^{3} \mathrm{~S}\right.$ levels from the $1 s 2 s$ configuration) are easily probed in the near-IR via strongly allowed electric dipole transitions. These transitions exhibit very large optical absorption cross-sections which can be calculated from:

$$
\int_{0}^{\infty} \sigma(v) d v=\frac{g_{2} A_{21} \lambda^{2}}{g_{1} 8 \pi}
$$

where $g_{2}$ and $g_{1}$ are the degeneracies of the upper and lower states respectively, $A_{21}$ is the Einstein Afactor, and $\lambda$ the optical wavelength. This gives the integrated cross section in units of $\mathrm{m}^{2} \mathrm{~Hz}$, which can then be converted to convenient units of $\mathrm{cm}^{2} \mathrm{~cm}^{-1}$ by multiplying by $10^{2} / c$, where $c$ is the speed of 
light. Extension of this relation to take into account absorption line shape, molecular absorption and ro-vibrational population can be found in the review by Reuter et al. ${ }^{131}$ Measured signals are that of line-of-sight absorption, which, assuming cylindrical symmetry and recording the radial dependence of these signals, can be readily reduced to absolute number densities using an inverse-Abel transformation ${ }^{132}$. The absorption is the product of the absorption cross-section, the number density $(N)$ of absorbing species, and the path length $(L)$, and is related to measurements through the BeerLambert law (where the absorption coefficient $\alpha=\sigma N$ ). It should be noted that the absorption signal depends upon the population difference between the lower and upper states of the transition being probed. This can sometimes lead to ambiguity especially in plasma spectroscopy, where the states in question may be close together in energy and where production rates of the states might be similar (usually electron impact rates in the case of a plasma). One advantage of using absorption spectroscopy is that, in principle, the temporal resolution is limited only by the detection instrumentation, and with little effort ns time response is possible, although this is tempered by the required bandwidth to detect with a particular sensitivity. Furthermore, by achieving a tight optical focus, beam waist sizes of $\sim 10-\sim 50 \mu \mathrm{m}$ are easily attainable. Thus a CAP plume can be mapped spatiotemporally with relatively good precision. An example of this from our laboratory is shown in figure 2 in a He discharge containing 1\% Ar. Measurements were made on the $\operatorname{Ar}\left(1 s_{5} \rightarrow 2 p_{6}\right)$ transition at $763.72 \mathrm{~nm}$ using a VCSEL laser, mapping the plume radially $(r)$. Figure $2(\mathrm{~A})$ shows the raw absorption signal with the laser wavelength tuned to the absorption at line-centre, and where there is one streamer-like discharge event per semi-phase of the driving voltage. The maximum measured absorption in the negative phase of the $\mathrm{HV}$, as a function of $r$, is shown in (B) and the consequent Abel transformed data in (C) showing evidence of the well-known annularity observed in these systems.

Strong absorption transitions invariably exist for many molecular radical species in the UV and mid-IR spectral regions. In the UV these are usually dipole allowed electronic transitions and in the mid-IR fundamental (i.e. $\Delta v=1$ ) rovibrational transitions. Ozone, though not a radical, is a reactive species prevalent in atmospheric pressure oxygen plasmas, or where plasma interacts with the ambient air, and ozone absorbs strongly between ca. $220 \mathrm{~nm}$ and $300 \mathrm{~nm}$ in the Hartley band ${ }^{134-137}$ with a maximum cross-section of $\sim 10^{-17} \mathrm{~cm}^{2}$. This has made ozone measurements accessible using mercury or $D_{2}$ lamp sources ${ }^{138-142}$, and thus it has been extensively studied. One potential drawback of probing ozone at this wavelength is the non-specificity resulting from the featureless absorption and therefore the possibility that other species that also absorb at this wavelength will cause erroneous results. Other UV sources such as KrF excimer lasers, ${ }^{143-145}$ and UV LEDs ${ }^{146}$ have also been utilised to measure ozone. Even VUV synchrotron radiation has been utilised for CAP spectroscopy; a major advantage of these sources is that they produce a high fluence UV continuum. However, in general, VUV spectroscopy has seldom been utilised to probe CAPs, as such sources can require extensive vacuum coupling; to our knowledge there have only been studies, on $\mathrm{O}\left({ }^{3} \mathrm{P}\right)$ and $\mathrm{N}\left({ }^{4} \mathrm{~S}\right)^{147,148}$, where the rf-CAP has been designed as part of a cell incorporating $\mathrm{MgF}_{2}$ windows.

At the other end of the spectral scale another ubiquitous radical species, NO has been studied rigorously in a nanosecond repetitively pulsed and plasma jet devices using both tuneable diode laser spectroscopy and quantum cascade laser absorption spectroscopy at ca. $1900 \mathrm{~cm}^{-1}(5.26 \mu \mathrm{m})^{149-151}$. Notably, Douat et al. ${ }^{150}$ were able to measure $10 \mathrm{ppm}$ NO in a micro-atmospheric pressure plasma jet with a mixture of $\mathrm{He}: \mathrm{N}_{2}: \mathrm{O}_{2}$ 99.5:0.36:0.07 downstream using a Herriott cell.

Cavity enhanced absorption spectroscopy ${ }^{152,153}$ is a sensitive absolute measurement technique that has become universally applied in many different fields. One of the most commonly used experimental formulisms is cw-cavity ringdown spectroscopy (cw-CRDS), ${ }^{154}$ where the light source is 
usually a semiconductor laser. Light from the laser is coupled into a high finesse optical cavity and its temporal decay measured after a low order mode (usually TEM $\mathrm{M}_{00}$ ) is excited; the time taken for the light intensity to drop to $1 / e$ of its initial value is known as the ringdown time, $\tau$. If there is an absorbing species present, the decay will be faster than in its absence, and the difference in the decay rate constants yields the absorption coefficient $(\alpha)$ and hence allows determination of absolute number densities. $\alpha$ can be readily calculated through the equation:

$$
\left(\frac{1}{\tau_{a b}}-\frac{1}{\tau_{0}}\right)=\alpha c
$$

where $\tau_{a b}$ and $\tau_{0}$ are the measured ringdown times with and without absorber present, and $\mathrm{c}$ is the speed of light. In CRDS the sensitivity comes from both the effective pathlength (for a $1 \mathrm{~m}$ length high finesse cavity with mirrors of $R=99.99 \%$, the effective optical pathength, $L_{\text {eff }}$, is $10 \mathrm{~km}$ ), and the fact that the measurement is made in the time domain and so is impervious to amplitude fluctuations.

Cavity enhanced schemes have been widely used to probe reactive species in low pressure plasmas, where the usually extended plasma has a dimension of the order of the physical length of the optical cavity. Notably, and of relevance to active species found in CAPs, Williams et al. have used integrated cavity output spectroscopy (ICOS) ${ }^{155,156}$ to record the absolute number densities of the $\mathrm{a}^{1} \Delta_{\mathrm{g}}$ state of molecular oxygen in an rf discharge at $\sim 30$ Torr, while $\mathrm{O}\left({ }^{3} \mathrm{P}\right), \mathrm{N}_{2}(\mathrm{~A})$ and radical species such as $\mathrm{NH}_{\mathrm{x}}$ and $\mathrm{CH}_{x}$ have been both extensively and quantitatively studied using cavity enhanced spectroscopy in reduced pressure devices. ${ }^{157-168}$ In comparison to CRDS, ICOS (also referred to as cavity enhanced absorption spectroscopy or CEAS in the literature) measures the time-integrated light intensity transmitted through the optical cavity, which is aligned such that its transmission function is as uniform as possible. The effective optical pathlengths in this case are usually (slightly) smaller than for CRDS. In CAP devices, where the active region is very small and because of the pressure, other factors such as Rayleigh scattering can limit the pathlengths achievable, there have been fewer studies. Despite these issues, Wang et al. have used pulsed-laser CRDS at $308 \mathrm{~nm}$ to measure the $\mathrm{OH}$ radical in-situ along the propagation direction of a CAP plume, ${ }^{169-171}$ while Laux et al. have measured $\mathrm{N}_{2}{ }^{+}$concentrations ( $\sim 390 \mathrm{~nm}$ ) but in a much larger atmospheric pressure discharge (diameter $\sim 7$ $\mathrm{cm})^{172}$, and Stancu et al. have measured $\mathrm{N}_{2}(\mathrm{~A})(770 \mathrm{~nm})$ in a nanosecond pulsed discharge. ${ }^{173}$ Measurements of $\mathrm{O}_{2}\left(\mathrm{a}^{1} \Delta_{\mathrm{g}}\right)$ in CAPs have been thus far limited to near-IR OES. ${ }^{174,175}$

Spatially, with relevance to directly probing CAP devices, the resolution of cavity enhanced techniques is limited by the size of the TEM ${ }_{00}$ Gaussian beam waist $\omega_{0}$ supported by the optical cavity. This is given by:

$$
\omega_{0}^{2}=\frac{L \lambda}{\pi} \sqrt{\frac{g_{1} g_{2}\left(1-g_{1} g_{2}\right)}{\left(g_{1}+g_{2}-2 g_{1} g_{2}\right)^{2}}}
$$

where $L$ is the mirror spacing, $\lambda$ is the wavelength, and $g_{1}$ and $g_{2}$ are the resonator ' $g$ ' parameters (1$L / r_{n}$ where $r_{n}$ is the radius of curvature of mirror $n$; and not to be confused with degeneracies earlier). Thus, a short $(20 \mathrm{~cm})$ optical cavity with mirrors of radii of curvature $0.3 \mathrm{~m}$ would present a TEM $\mathrm{M}_{00}$ mode with a waist of $\sim 200 \mu \mathrm{m}$ at $1500 \mathrm{~nm}$. Note that one would expect this limit only to be relevant to a technique where a single cavity mode is excited; the average optical field diameter for a method such as pulsed CRDS could be much higher unless accurate optical mode matching is achieved. Clearly there is also a finite time response associated with an optical cavity and in most cases such a FabryPerot device can be considered a first order low-pass filter of bandwidth defined by $1 / \tau$ (the reciprocal of the ringdown time). With a pulsed CRDS system however it is possible to infer some intra-ringdown 
information, with Stancu et al. ${ }^{173}$ realising a $50 \mathrm{~ns}$ time resolution within a microsecond ringdown time in tracking the temporal evolution of $\mathrm{N}_{2}\left(\mathrm{~A}^{3} \Sigma_{\mathrm{u}}{ }^{+}\right)$in a nanosecond repetitively pulsed discharge.

More recently an alternative cavity strategy has been employed by Gianella et al. ${ }^{176}$ who have utilised optical feedback cavity enhanced absorption spectroscopy (OF-CEAS) ${ }^{177}$ to measure the $\mathrm{HO}_{2}$ radical from a CAP source (a KINPen-Sci ${ }^{178}$ ). The same authors have also undertaken both direct and indirect cavity ringdown measurements, examining the influence of curtain gas on the production of $\mathrm{HO}_{2}$ confirming the findings from the previous OF-CEAS experiments and explaining the results in terms of a spatio-dynamic kinetic model. ${ }^{179}$ The indirect method employs a sampling procedure in order to transfer the effluent of the CAP into a high finesse cavity working at reduced pressure. While this means a loss of spatio-temporal information and an introduction of uncertainty in the absolute number densities generated by the CAP, it does mean that some of the most sensitive measurements can be made as the twin effects of turbulence and pressure broadening are removed or, at least, minimised. So although both CRDS and OF-CEAS were sensitive enough for accurate $\mathrm{HO}_{2}$ determination, the indirect CRDS measurements were found to have a lower limit of detection compared to those from the direct OF-CEAS and CRDS measurements of the jet, and a better specificity. It is worth noting that OF-CEAS relies on resonant radiation that has circulated through the optical cavity, injection seeding the diode laser and narrowing the linewidth of the laser to achieve stable and maximal cavity power build-up, and has generally achieved limits of detection as good as and surpassing that from CRDS. However, the OF-CEAS technique itself requires reproducible coupling between the laser and the cavity and this coherent mechanism is compromised when the CAP continuously impinges on the cavity when direct sampling is employed. Reduced pressure CRDS measurements of $\mathrm{HO}_{2}$ are shown in figure 3 from the KINPen CAP source. Data in figure 3(a) has a baseline noise level of $\sim 10^{-10} \mathrm{~cm}^{-1}$; a fit to the data is also shown for two different curtain gas constituencies. Figure 3(b) illustrates how the $\mathrm{HO}_{2}$ concentration varies as a function of the oxygen content of the curtain gas: some $\mathrm{HO}_{2}$ is produced with no curtain gas oxygen, implying that moisture in the carrier gas (argon) is also a potential source of $\mathrm{HO}_{2} \cdot{ }^{179}$

Another interesting technique suitable for radical detection is Faraday rotation spectroscopy (FRS), which exploits the Faraday effect for the selective detection of paramagnetic species. This involves measuring the rotation of the plane of polarized light upon interaction with a paramagnetic substance in the presence of a longitudinal magnetic field. FRS quantifies this rotation with the Faraday rotation angle, $\theta$, which is dependent on the concentration of the paramagnetic substance, the pressure, and the field strength and offers an inherently sensitive means of detecting paramagnetic molecules with limited interference from diamagnetic species. Pioneered by Liftin et al. ${ }^{180}$ in 1980 on the $\mathrm{OH}$ radical, the technique has since been developed for the detection of a range of paramagnetic molecules, including $\mathrm{HO}_{2}{ }^{181}$ with a noise equivalent (bandwidth-normalized) rotation angle of $8.9 \mathrm{nrad} \mathrm{Hz}{ }^{-1 / 2}$ corresponding to $0.35 \mathrm{ppmv} \mathrm{Hz}^{-1 / 2}$ of $\mathrm{HO}_{2}$. In FRS the rotation angle is cumulative, so the more passes the light makes through the sample in the magnetic field, the larger the rotation signal. Thus, coupling a high finesse cavity-enhanced technique with FRS can improve sensitivity through a significant increase in the interaction length. Engeln et al. ${ }^{182}$ reported the first experimental demonstration of cavity enhanced polarization spectroscopy to probe the $b^{1} \Sigma^{+} \mathrm{g} \leftarrow X^{3} \Sigma^{-} \mathrm{g}$ transition of molecular oxygen. More recently, quantum cascade laser optical feedback cavity enhanced spectroscopy has been paired with Faraday modulation to detect NO. ${ }^{183}$ With very competitive detection limits, this technique has now also been extended to $\mathrm{HO}_{2}$ with an equivalent CRDS device ${ }^{184}$, and figure 4 depicts both the experiment arrangement and data from this study. High currents are required to generate the magnetic field within the cooled solenoid. The Faraday rotation 
angle $\theta$ is related to the measured cavity ringdown times for the orthogonal polarisations $\left(\tau_{s}\right.$ and $\left.\tau_{p}\right)$ by:

$$
\theta=\frac{L}{4 c}\left(\frac{1}{\tau_{s}}-\frac{1}{\tau_{p}}\right)
$$

We estimate that the limit of detection for $\mathrm{HO}_{2}$ from this experiment is $\sim 4$ times smaller than the equivalent CRDS experiment (i.e. same optical enhancement cavity) and is $<7 \times 10^{7}$ molecules $\mathrm{cm}^{-3}$ (at 30 Torr).

Given the multi-component nature of CAPs, a spectroscopic tool that is capable of simultaneous detection across a wide spectral range and with high resolution is extremely attractive. Optical frequency combs (OFCs) are such light sources. ${ }^{185-189}$ These devices are femtosecond laser sources whose output in the frequency domain consists of a series of narrow, equally spaced modes with a known, and controllable, frequency and with a very well-defined phase relationship between them, i.e. a comb of frequencies (see figure $5 a, b$ ). The comb arises from the interference of a train of equally spaced pulses in the time domain and the frequency spacing between modes is simply given by the inverse of the time between consecutive pulses. This repetition rate, $f_{\text {rep }}$, is determined by the optical pathlength inside the femtosecond laser resonator while the inverse of the pulse duration determines the frequency domain spectral bandwidth. With these devices one must also consider the pulse-topulse phase shift of the electric-field carrier wave relative to the pulse envelope, $\Delta \phi$ (known as the carrier-envelope phase shift), which shifts the modes in the frequency domain such that the frequency of the $m^{\text {th }}$ mode ( $m$ is an integer) is given by $v_{m}=m f_{\text {rep }}+f_{0}$; here $f_{0}$ is the carrier-envelope offset frequency due to the carrier-envelope phase shift, and is given by $\left(f_{\text {rep }} \Delta \phi / 2 \pi\right)$. Elegant up-conversion methods for determining $f_{0}$ have been developed with the result that OFCs offer state-of-the art performance for both frequency and time metrology. ${ }^{190,191}$ Furthermore, these devices are sufficiently rugged that both near-IR and mid-IR OFCs are now commercially available (see for example, Menlo Systems GmbH, Germany; Laser Quantum, UK; Toptica Photonics AG, Germany).

In terms of molecular spectroscopy, OFCs have several advantages in comparison to more commonly used sources such as $\mathrm{cw}$ diode lasers or incoherent (broadband) light sources such as LEDS. These include simultaneous acquisition over many thousands of channels, enabling measurement of many different spectroscopic transitions, while retaining high spectral resolution ${ }^{192-196}$ - in the latter case the frequency resolution is limited by the linewidth of a single tooth of the comb, which can be sub-Hz. ${ }^{197}$ OFCs therefore provide the high resolution of $\mathrm{cw}$ laser spectroscopy, while removing the requirements for frequency scanning and thereby eliminating the effects of experimental drift. Furthermore, due to the highly regular structure of its spectral output, OFCs can be efficiently coupled to optical cavities, thereby increasing the effective interaction length with the sample. Such Cavityenhanced direct frequency comb spectroscopy (CE-DFCS) therefore provides ultrasensitive absorption measurements over a wide spectral range and with acquisition times shorter than a second. ${ }^{198}$ There are now myriad examples of CE-DFCS for molecular spectroscopy with a variety of comb sources and schemes for broadband, simultaneous detection, and the interested reader is directed one of many excellent reviews in this area. ${ }^{194,195,199,200,201}$ Figure $5 \mathrm{c}$ shows data from a near-IR frequency comb multipass optical absorption experiment on the analysis of acetylene, illustrating the broad spectral coverage, sensitivity and specificity achievable. ${ }^{203}$

Despite the clear advantages of OFCs for plasma analysis, a field which could take advantage of the rapid, massively parallel acquisition afforded by OFC spectroscopy, there is to our knowledge only one previously reported study in this area, which is that by Golkowski et al. ${ }^{204}$ who used a mid-IR comb 
in combination with a multi-pass cell ( $36 \mathrm{~m}$ pathlength) to probe the effluent of a non-thermal medical plasma. Measurements were conducted at a total pressure of 620 Torr and $\mathrm{O}_{3}, \mathrm{~N}_{2} \mathrm{O}, \mathrm{NO}_{2}$ and $\mathrm{H}_{2} \mathrm{O}_{2}$ were detected at volume mixing ratios of 724, 23, 11 and 4 ppm, respectively. Significantly (and perhaps unexpectedly) the measurements also confirmed the presence of formaldehyde, $\mathrm{H}_{2} \mathrm{CO}$, at a level of $700 \mathrm{ppb}$, illustrating the power of this broadband yet high resolution method. We note that this example does not utilise an optical cavity and we expect that CE-DFCS will afford many interesting insights into the low temperature oxidation chemistry occurring in CAP devices. ${ }^{194,199,200,205-214}$ Recent advances in OFC spectroscopy have included combining the frequency comb with Faraday rotation spectroscopy, as demonstrated on mid-IR measurements of $\mathrm{NO}^{215}$ and developing methodologies with fast temporal response within optical enhancement cavities. ${ }^{216}$

\section{Interfaces and bulk liquid measurements}

As noted in the introduction, reactive species are generated either within the CAP or upon its interaction with the ambient atmosphere. The resulting family of primary RONS consists of various atomic, radical, ionic, and molecular species, such as $\mathrm{O}, \mathrm{O}_{3},{ }^{1} \mathrm{O}_{2}, \mathrm{OH}, \mathrm{O}_{2}^{-}, \mathrm{HO}_{2}, \mathrm{NO}, \mathrm{ONOO}^{-}$and OONOO- $\mathrm{H}_{2} \mathrm{O}_{2}, \mathrm{NO}_{2}^{-}, \mathrm{NO}_{3}^{-}$; the concentration of negative ions can be significant because of the accumulation of $\mathrm{O}_{3}$ and $\mathrm{NO}_{x}$ which readily undergo (dissociative) electron attachment. These RONS are responsible for plasma-induced effects in bio-fluids, which may be beneficial (or deleterious in some cases!). Liquid water is ubiquitous in biological systems and several of the primary RONS, such as $\mathrm{OH}, \mathrm{NO}, \mathrm{H}_{2} \mathrm{O}_{2}, \mathrm{O}, \mathrm{O}_{3}$, which are created predominantly in the gas phase, undergo chemical reactions in the liquid phase to yield secondary RONS. The quantitative detection of both primary and secondary RONS is crucial for understanding and tailoring CAPs for specific applications.

Given the wide range of chemical species generated both in the plasma and upon its interaction with its environment, experimental gas-phase measurements on selected species have necessarily been augmented by chemical kinetic models (see for example, references ${ }^{217-221}$ ). These models not only predict the abundances and lifetimes of gas phase species but now address the interaction of gas-phase RONS with aqueous solutions; an example of the predicted concentrations and lifetimes of species in the condensed phase are shown in figure 6 which is from the work of Lietz and Kushner. ${ }^{219}$ The figure shows calculated number densities of both major $\left(>10^{14} \mathrm{~cm}^{-3}\right)$ and minor $\left(<10^{13} \mathrm{~cm}^{-3}\right)$ liquid phase components of plasma treated water as a function of time after treatment. The figure also clearly shows that the plasma treated water becomes acidified; acids that are produced in the gas phase and subsequently dissolve into the water as well as those that are generated directly within the condensed phase contribute to this overall decrease in $\mathrm{pH}$. Much like the gas-phase chemistry, there is a large number of species present in the condensed phase covering a wide range of concentrations and lifetimes, which can make the experimental monitoring of RONS in the liquid phase challenging. Such studies are however crucial for model benchmarking and in the next section we consider methods that can be used to achieve this aim.

\section{A. Optical Methods}

Probably the most straightforward and commonly used method for detecting RONS is by absorption in the UV-visible region of the electromagnetic spectrum. The instrumentation used is generic and available in all laboratories equipped for elementary chemical analysis. A pertinent 
example here is the direct detection of $\mathrm{ONOO}^{-}$via UV absorption ${ }^{58}$, though we note that $\mathrm{ONOO}^{-}$was stabilised by ensuring that the sample was at high $\mathrm{pH}$ - see figure 6. Absorption spectroscopy is attractive as it is both non-destructive and allows the presence of multiple RONS to be determined simultaneously. On the downside the instrumentation is not particularly sensitive nor does it have fast time resolution. As such, it is useful only in probing relatively stable liquid phase species. Furthermore, direct UV absorption tends to lack specificity, as liquid-borne species such as $\mathrm{H}_{2} \mathrm{O}_{2}, \mathrm{NO}_{2}{ }^{-}, \mathrm{NO}_{3}{ }^{-}$and ONOO- exhibit broad overlapping absorption features.

Indirect detection, in which RONS species are detected after reaction with a chemical probe, has also been widely used. Examples here include the use of coloured dyes such as methylene blue and red which are degraded by reaction with CAP-induced RONS, and the loss of colour quantified using UV-vis absorption. ${ }^{222,223}$ The main disadvantage in this case is the non-specific degradation of such dyes, e.g. methylene blue is degraded by reactions with $\mathrm{OH}, \mathrm{O}$, and $\mathrm{O}_{3} \cdot \mathrm{O}_{2}{ }^{-}$can also be detected by degradation of dyes with similar selectivity issues ${ }^{224}$. In a similar vein, indirect fluorescence may be used such as in the case of using terephthalic acid to detect $\mathrm{OH}$ in the liquid phase ${ }^{225}$. Again, specificity is an issue as the fluorescence of $\mathrm{OH}$-substituted terephthalic acid can be affected by other oxidants present in solution. ${ }^{226}$ The well-known Griess assay (a colorimetric test) is a similar example for the detection of nitrites in liquid ${ }^{(e . g .227)}$ where the presence of diazonium salts, formed by reaction with sulphanilic acid, is tested for using an azo-dye. The azo-dye can then be probed by optical absorbance at $548 \mathrm{~nm}$. In summary, optical spectroscopic methods can provide both qualitative and semiquantitative detection of RONS but in many cases the detection is non-specific.

Traditionally, attenuated total internal reflection (ATR) methodologies have been used to determine and quantify surface-borne species, but are also sensitive to species just above the surface, or within a liquid upon a surface (the evanescent field of the light penetrates a distance on the order of $\lambda$ ). These conventional methods for probing liquid/gas interfaces have been demonstrated recently on an interesting esoteric species generated by a plasma: the solvated electron. Rumbach et al. ${ }^{228,229}$ used ATR to probe this species, measuring across a broad visible range and identifying the expected maximum absorption at $\sim 700 \mathrm{~nm}$. Generally, however, for the detection of radical species, ATR is not sensitive enough, unless its basic principles are combined somehow with an enhancement technique. Such developments have been demonstrated, particularly evanescent wave (EW) cavity-enhanced methods such as EW-CRDS, which have sometimes included the fabrication of special prismatic optics to generate high finesse monolithic resonators. ${ }^{230,231}$ These methods have been used to probe liquidborne species and interfacial processes, ${ }^{232-234}$ and to measure absolute surface coverage ${ }^{235}$ even in plasma studies (low pressure) looking at dangling bond formation in amorphous $\mathrm{Si}: \mathrm{H}^{236,237}$, but to our knowledge have never been used to study CAP-induced chemistry.

Currently amongst the best reported sensitivities for such an experiment is a minimum detectable absorption of $1 \times 10^{-7} .235$ However, such a device may only probe an effective volume of $1 \mathrm{~mm}^{2} \times 1 \mu \mathrm{m}$ $=10^{-6} \mathrm{~cm}^{3}$ i.e. a volume element of linear dimension $10^{-2} \mathrm{~cm}$. For an absorption of $1 \times 10^{-7}$, this yields a minimum detectable absorption coefficient, $\alpha_{\min }$, of $10^{-5} \mathrm{~cm}^{-1}$. If for example, the absorption crosssection $\sigma$ is $10^{-17} \mathrm{~cm}^{2}$ this translates into a minimum detectable number density, $N_{\min }$, of $10^{12} \mathrm{~cm}^{-3}$; if $\sigma$ is $10^{-20} \mathrm{~cm}^{2}$ then $N_{\min }$ will correspondingly increase to $10^{15} \mathrm{~cm}^{-3}$. With reference to figure 6 , it is clear that EW-CRDS and EW-CEAS are capable of probing a reasonable number of the more prevalent liquid phase RONS and may be good enough to probe, for example, $\mathrm{NO}_{x}$ species in the plasma afterglow.

Another optical technique that provides regional and molecular specificity is vibrational sumfrequency generation (VSFG). ${ }^{238-240}$ Used historically to probe surface/layer borne species this technique uses two pump lasers which interact at the point of mutual focus and utilises the molecule's 
vibrational resonance to enhance the generation of a sum frequency signal. Pertinent examples include the work by Kondo et al. $^{238}$ to probe the air/water interface exposed to a dielectric barrier discharge. Here the second harmonic of an Nd:YAG laser $(532 \mathrm{~nm})$ is combined with a tunable mid-IR beam $\left(3100-3770 \mathrm{~cm}^{-1}\right)$ from an OPO/OPA device and sum-frequency signals recorded at visible wavelengths between $443 \mathrm{~nm}$ and $457 \mathrm{~nm}$. A schematic of their experiments is shown in figure 7 . Probing $\mathrm{OH}$ to identify free $\mathrm{OH}$, pseudo liquid-like, and ice-like structures present at the water interface exposed to a DBD, Kondo et al. concluded that the air/water interfacial structure is influenced predominantly by the gas-phase neutral species present and not only by solutes: the interfacial structures are efficiently perturbed by the adsorbed reactive neutral species, even though the densities in the bulk are negligibly small, and neither the electric field nor the UV flux seem to have strong immediate influence. VSFG is a background free technique with signals that depend on the product of the laser intensities and the square of the second order susceptibility of the molecular ensemble which for VSFG consists of a non-resonant (matrix) and resonant term (target). Even if beam waists can be properly accounted for, the susceptibility term makes VSFG signals difficult to quantify absolutely, especially for evolving chemical environments. Nevertheless, VSFG remains a useful site specific technique with potentially high temporal resolution.

\section{B. Non-optical methods}

Electron Paramagnetic Resonance spectroscopy (EPR, or ESR - electron spin resonance) is a wellestablished method for detecting radical species in solution ${ }^{241-243}$, and is based upon the use of microwave radiation to induce a spin-flip in the (one or more) unpaired electrons in the radical of interest. However, in the liquid environment most radical species are short-lived in comparison to the ESR measurement timescale, and are therefore difficult (or impossible) to monitor directly. One technique to circumvent this problem is called spin trapping whereby a more stable spin-adduct is formed prior to EPR analysis. ${ }^{242}$ In order to achieve this, reagents (usually nitrones) which target particular radicals are added to the solution of interest and a long-lived adduct formed. A second method is to use a spin probe: usually a hydroxylamine of a stable nitroxide. Here, the radical of interest abstracts the $\mathrm{H}$ atom from the hydroxylamine group and the resultant stable nitroxide radical is measured. Both methods of radical detection have been widely used to study CAP-liquid systems and been shown to be viable methods for detecting several transient radical species (spin adduct/probe in brackets) including $\mathrm{H}(\mathrm{DMPO})^{244-246}(\mathrm{PBN})^{59,245-248}\left(\mathrm{M}_{4} \mathrm{PO}\right)^{246}$; NO $\left((\mathrm{DETC})_{2}-\mathrm{Fe}_{2}{ }^{+}\right)^{249}$

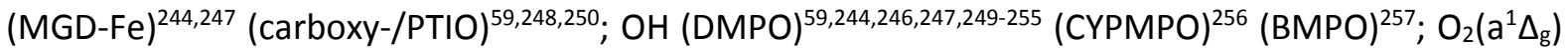
$(\text { TEMP) })^{59,249,251,253}$ (CYPMPO) ${ }^{256}$ (TPC) ${ }^{244} ; \mathrm{O}_{2}^{-}$(DMPO) ${ }^{254,257}$ (BMPO) $^{257}$ (DEPMPO) ${ }^{247}$ (CYPMPO) ${ }^{250}$; and $\mathrm{CH}_{\mathrm{x}}(\mathrm{DBNBS})^{255}$. EPR has the advantages that many radicals can be identified simultaneously and with high selectivity.

EPR detection of RONS however is not without its problems. As perhaps expected, these are related to the non-selective reactions of both the spin probes and spin traps. Relevant examples include the use of the spin probe TEMPONE-H to detect $\mathrm{O}_{2}^{-}$, NO and $\mathrm{ONOO}^{-}$but which also reacts with $\mathrm{OH}$, and the oxidation of hydroxylamines of stable nitroxides by $\mathrm{O}_{2}, \mathrm{O}_{3}, \mathrm{O}$ and other reactive oxygen species - see below. It should be noted however that the non-selectivity of spin trapping can be useful as many radicals can be identified simultaneously from the same EPR spectrum. A further limitation is the oxidation of both spin traps and decay of spin adducts by plasma-induced RONS such as $\mathrm{O}_{3}, \mathrm{OH}$, $\mathrm{O}$, and solvated electrons. While this does not generally present a problem due to a large excess of spin trap molecules, in cases where mass transfer is limited, this can result in only the topmost layer of solution reacting with RONS, leading to a decrease in the EPR signal. It is therefore important to 
monitor the temporal changes in the adduct concentration over the course of a measurement. Finally, it should be emphasised that while the absolute concentrations of radical adducts can be determined by calibration with samples of stable radicals of known concentration, these do not represent the sum total of radicals produced in the liquid phase; competing reactions such as recombination and reactions with both water and organic molecules occur, limiting the concentration of trapped radicals. Nevertheless, the change in the concentration of trapped radicals does track the change in the total radical concentration, and so qualitative behaviour can be established. For more information the interested reader is referred to the excellent recent review by Gorbanov et al. ${ }^{258}$

Liquid chromatography-mass spectrometry (LC-MS) is a universal platform technology that allows sensitive detection of stable RONS, but with caveats with regard to selectivity and quantification. ${ }^{259,260}$ In the majority of cases the detection is indirect in that the first step in determining the presence of the RONS is to use a chemical reaction and to analyse the subsequent reaction products. Examples of reagents include amino acids, such as cysteine ${ }^{261}$ and modified Ltyrosine. ${ }^{262}$ In the latter case the nitration of tyrosine is non-selective and can occur in reactions with $\mathrm{ONOO}^{-}$and $\mathrm{NO}$, and with $\mathrm{NO}_{2}$ and $\mathrm{NO}_{2}{ }^{-}$. Similarly, aromatic substitution reactions of phenol allow detection of $\mathrm{O}, \mathrm{OH}, \mathrm{NO}$ and $\mathrm{NO}_{2}$. Nitration and nitrosation of phenols in combination with highperformance liquid chromatography (HPLC) analysis of the products can be used to detect $\mathrm{ONOO}^{-}$. Again, selectivity is a problem as several species can lead to the same reaction product; examples here include the formation of nitrosophenol from both $\mathrm{NO}$ and $\mathrm{ONOO}^{-}$, and nitrophenol from $\mathrm{NO}_{2}, \mathrm{HNO}_{2}$, and $\mathrm{HNO}_{3}$, respectively. It should be noted that the major chemical reactions are highly $\mathrm{pH}$ dependent ${ }^{263}$. Other examples include the hydroxylation of phenol which can occur both with $\mathrm{OH}^{264}$ and $\mathrm{O}$ atoms $\mathrm{s}^{265}$. Finally, we note that the spin trapping technique pioneered in EPR can be combined with LC-MS for detection of the adducts of DMPO and other nitrone spin traps. Yet again, there are caveats as nitroxides may decay during the electrospray ionization step in the sample preparation. ${ }^{266}$ Thus, chromatography and mass spectrometry are useful tools for detection of plasma-produced liquid-borne RONS, but the indirect way by which they sample means that quantitative analysis is nontrivial.

\section{Summary}

Cold atmospheric pressure plasmas afford a rich chemical environment with myriad applications. Key to much of the CAP induced chemistry is the presence of radical species, and the quantification of both the number densities of these species and their sources and sinks (stable molecules) is required for optimising future applications with these devices. It is clear that quantitative measurements across both the gas and liquid phases are necessary, and while much of this has been achieved there remains much still to be done. This review, though not exhaustive, has sought to present a selection of methods that have not only contributed to this endeavour, but may also provide advances in the future. This may well be manifest in a combination of techniques, for example, probing liquids directly with a broad band optical frequency comb source in combination with an enhancement cavity involving an evanescent wave sensing component, could be a viable method of achieving both selectivity and sensitivity. Generally, analysis in the gas phase is direct with most spectroscopic probes affording sufficient selectivity and sensitivity to confidently map out the chemical networks in operation. In contrast, analysis of liquid phase radicals generated by CAPs is predominantly indirect in that it is based upon spin trapping or probe modification with subsequent LC, MS, ESR, or UV-vis 
detection. CAP presents a (unique) challenge in that many types of RONS are present simultaneously which leads to non-selective formation of products that are detected, non-selective loss of reagents that are being monitored, and enhanced degradation of spin traps and adducts. Furthermore, we note that the reaction kinetics and pathways of RONS are $\mathrm{pH}$-dependent, adding an additional layer of complexity to the challenges of unravelling the details of the multi-timescale chemistry in these intriguing systems.

\section{Acknowledgements}

The authors would like to acknowledge the UK Engineering and Physical Sciences Research Council (EPSRC) for support provided within the standard research scheme (grant number EP/P026621/1). 
Figure 1

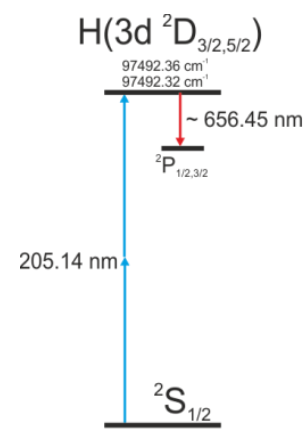

hydrogen

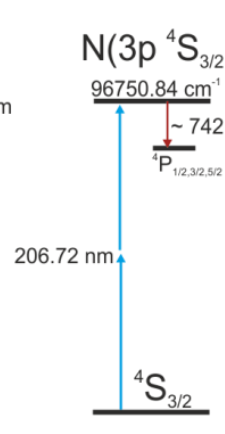

nitrogen

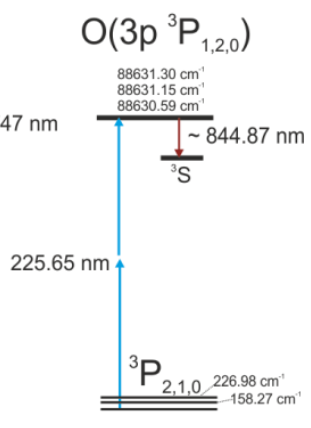

oxygen

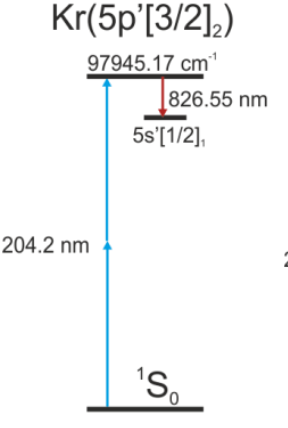

krypton

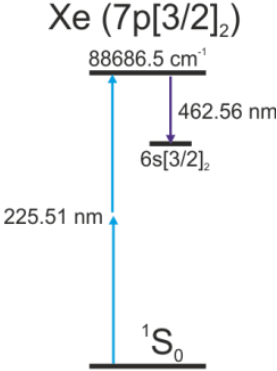

xenon

Figure 1. Two-photon excitation and fluorescence (TALIF) schemes for atomic hydrogen, nitrogen and oxygen, and calibration schemes with krypton and xenon. An alternative is also used for Xe, pumping to the $6 p^{\prime}[3 / 2]_{2}$ state at $89162.35 \mathrm{~cm}^{-1}$ (two photons of $224.3 \mathrm{~nm}$ ) and detecting subsequent fluorescence at $834.9 \mathrm{~nm}$ to the $6 \mathrm{~s}^{\prime}[1 / 2]_{1}$ state. All wavelengths are in vacuo. In fs-TALIF, all three spinorbit states of $\mathrm{O}\left({ }^{3} \mathrm{P}\right)$ can be excited simultaneously. 
Figure 2
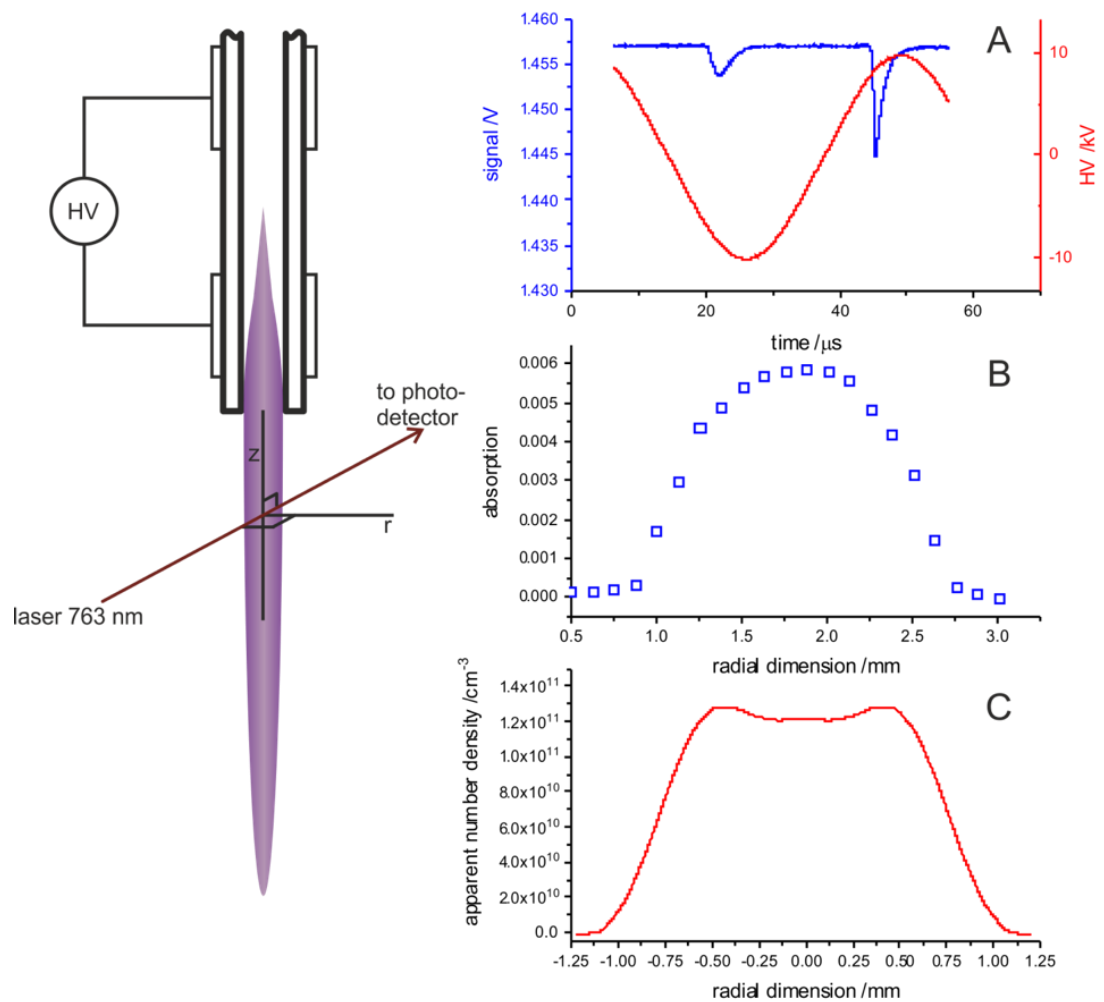

Figure 2: A schematic of the experimental geometry used to make time-resolved studies of atomic absorption within a CAP. (A) The time-resolved absorption of metastable Argon during a single cycle of the HV. In this case the diode laser wavelength is fixed at the line centre of the $\left(1 s_{5} \rightarrow 2 p_{6}\right)$ transition in $\mathrm{Ar}$ at $763.72 \mathrm{~nm}$. (B) Integrated transient absorption as a function of radial position; the maximum absorption is at the centre of the jet and occurs at a radial position of $c a .1 .8 \mathrm{~mm}$. (C) Abel inversion of the data in (B) yield the number densities of metastable argon as function of position with respect to the centre of the CAP jet. The annular structure of the plasma jet is a consequence of the influence of the interior dielectric surface on the discharge. ${ }^{133}$ 
Figure 3
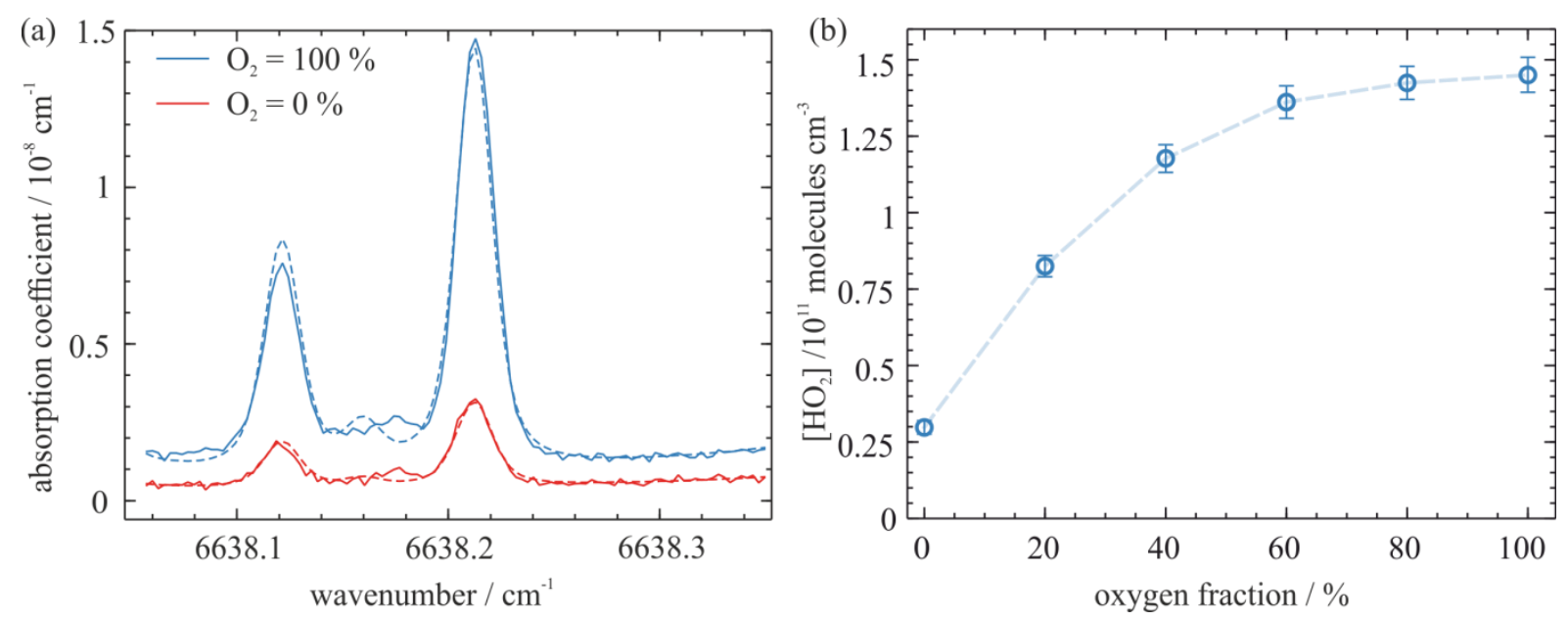

Figure 3: (a) CRDS spectra of $\mathrm{HO}_{2}$ radicals sampled from a CAP under conditions where the curtain gas is either formed only from $\mathrm{O}_{2}$ or is totally devoid of $\mathrm{O}_{2}$ (dashed lines are fits to the data: see [179]). The total pressure in the sample cell is 40 Torr. (b) The variation of $\mathrm{HO}_{2}$ number density as a function of $\mathrm{O}_{2}$ fraction in the curtain gas. Some $\mathrm{HO}_{2}$ is also formed because of the presence of water vapour in the argon carrier gas. 
Figure 4
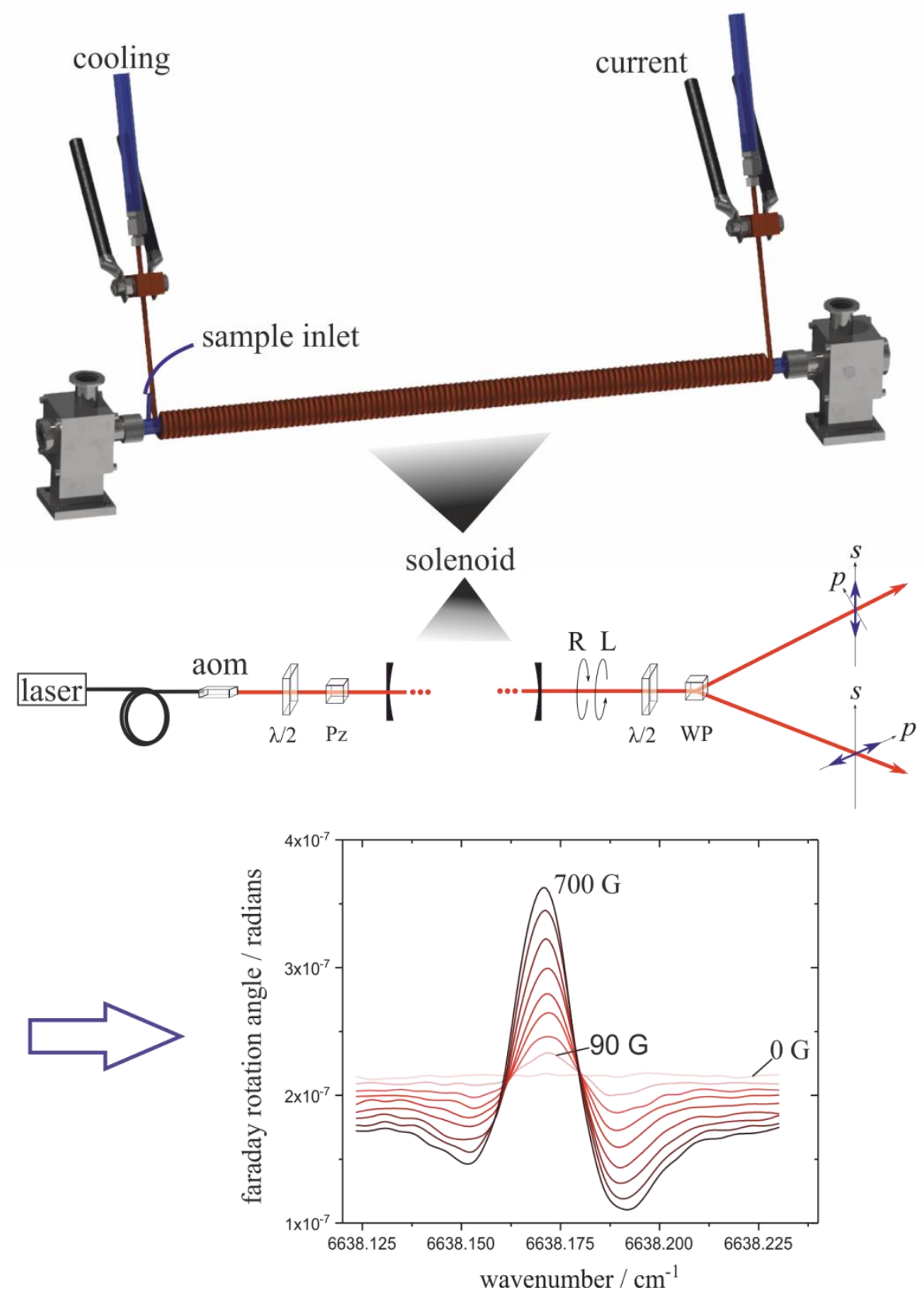

Figure 4: Schematic of a linear optical cavity (with mirror enclosures) consisting of a glass tube surrounded by a water-cooled solenoid. The current is varied between 0 and $400 \mathrm{~A}$ to obtain up to $700 \mathrm{G}$ of magnetic field strength. The cavity transmission can be considered a superposition of the two circular eigenpolarizations; a left (L) and right (R) hand circularly polarised wave. The Wollaston prism (WP) produces two diverging beams, each of which is a linear superposition of the two eigenpolarizations. The lower pane shows the FRS-CRDS spectra of $\mathrm{HO}_{2}$ radicals sampled from a CAP source under varying magnetic field strengths. The total pressure in the sample cell is 30 Torr. 
Figure 5

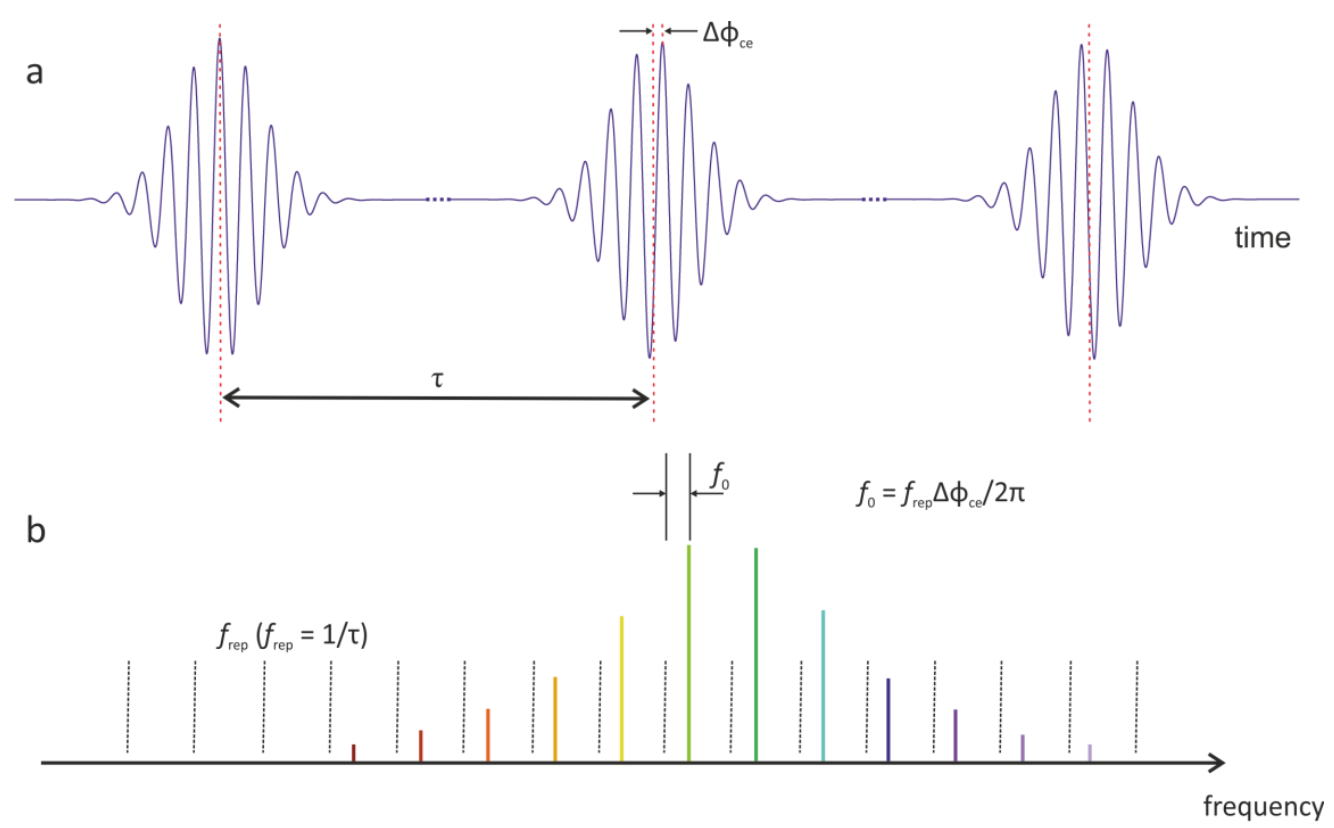

c

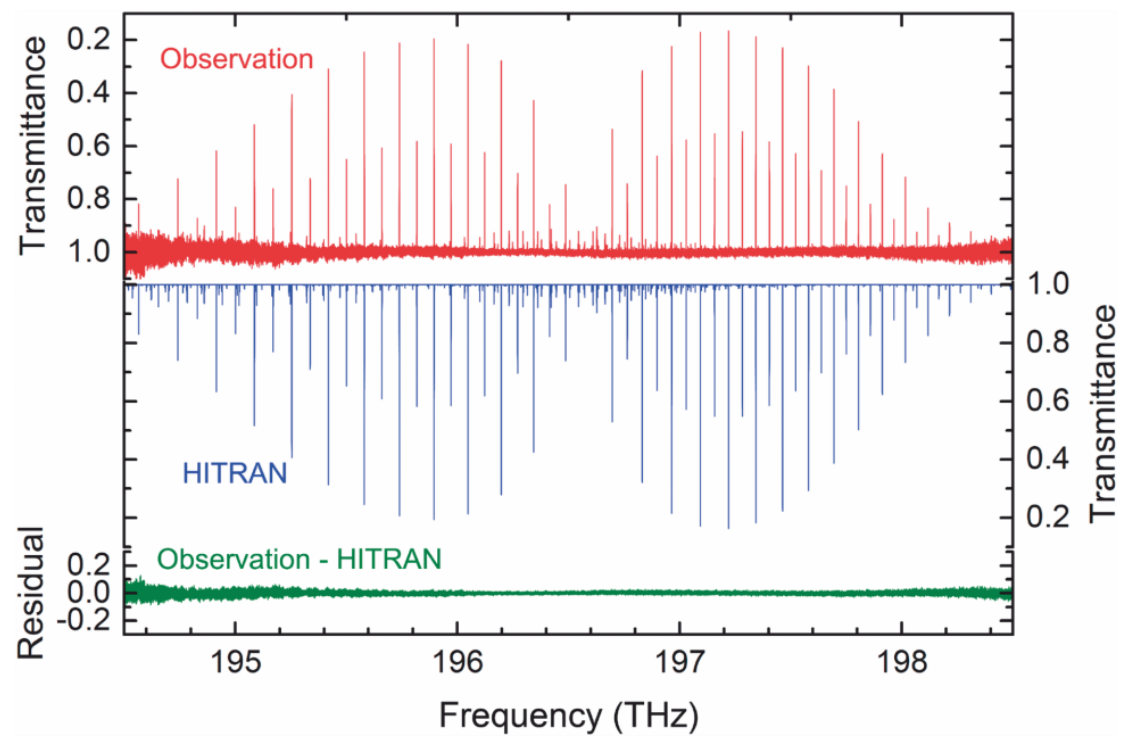

Figure 5: (a) Time-domain representation of a mode-locked laser pulse train and (b) the corresponding frequency-domain picture illustrating the frequency comb structure. In the time domain, pulses with the same intensity profile exhibit a regular separation given by the laser cavity's round-trip time $\tau$. However, due to intracavity dispersion, the electric-field oscillation experiences a pulse-to-pulse phase shift, $\Delta \phi_{\text {ce }}$, with respect to its envelope. The Fourier transform of this series of pulses results an expression for the frequency of every line $m$ of the frequency comb such that $v_{m}=m f_{\text {rep }}+f_{0}$, where $f_{\text {rep }}$ and $f_{0}$ are the laser repetition rate and comb offset frequency, respectively. (c) A near-IR frequency comb spectrum of the $v_{1}+v_{3}$ band of 0.45 Torr of ${ }^{12} \mathrm{C}_{2} \mathrm{H}_{2}$ at $1.52 \mu \mathrm{m}$ over $4 \mathrm{THz}\left(\sim 130 \mathrm{~cm}^{-1}\right)$ within a White cell (3.9 $\mathrm{m}$ total pathlength). The data are extracted using a dual comb interferometric method, and are compared to a simulation from the HITRAN database ${ }^{202}$ : reproduced from Okubo et al. ${ }^{203}$ 
Figure 6

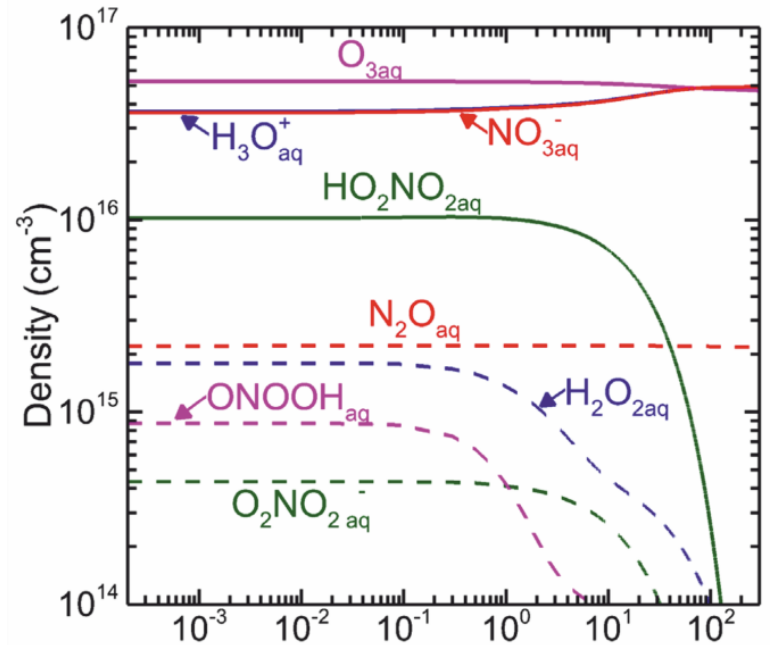

(a)

Time After Plasma (s)

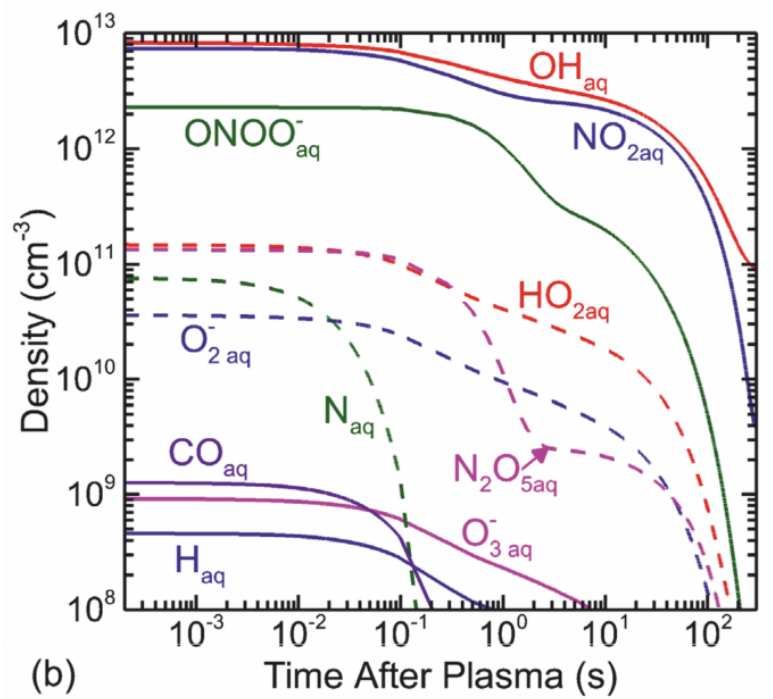

Figure 6: (a) Calculated number densities of major liquid phase components $\left(>10^{14} \mathrm{~cm}^{-3}\right)$ of plasma treated water and. (b) Calculated number densities of some minor liquid-phase components $\left(<10^{13}\right.$ $\mathrm{cm}^{-3}$ ) of plasma treated water both as a function of time after treatment (5000 pulses, $10 \mathrm{~s}$ of a dielectric barrier discharge). Reproduced from Lietz and Kushner. ${ }^{219}$ 
Figure 7

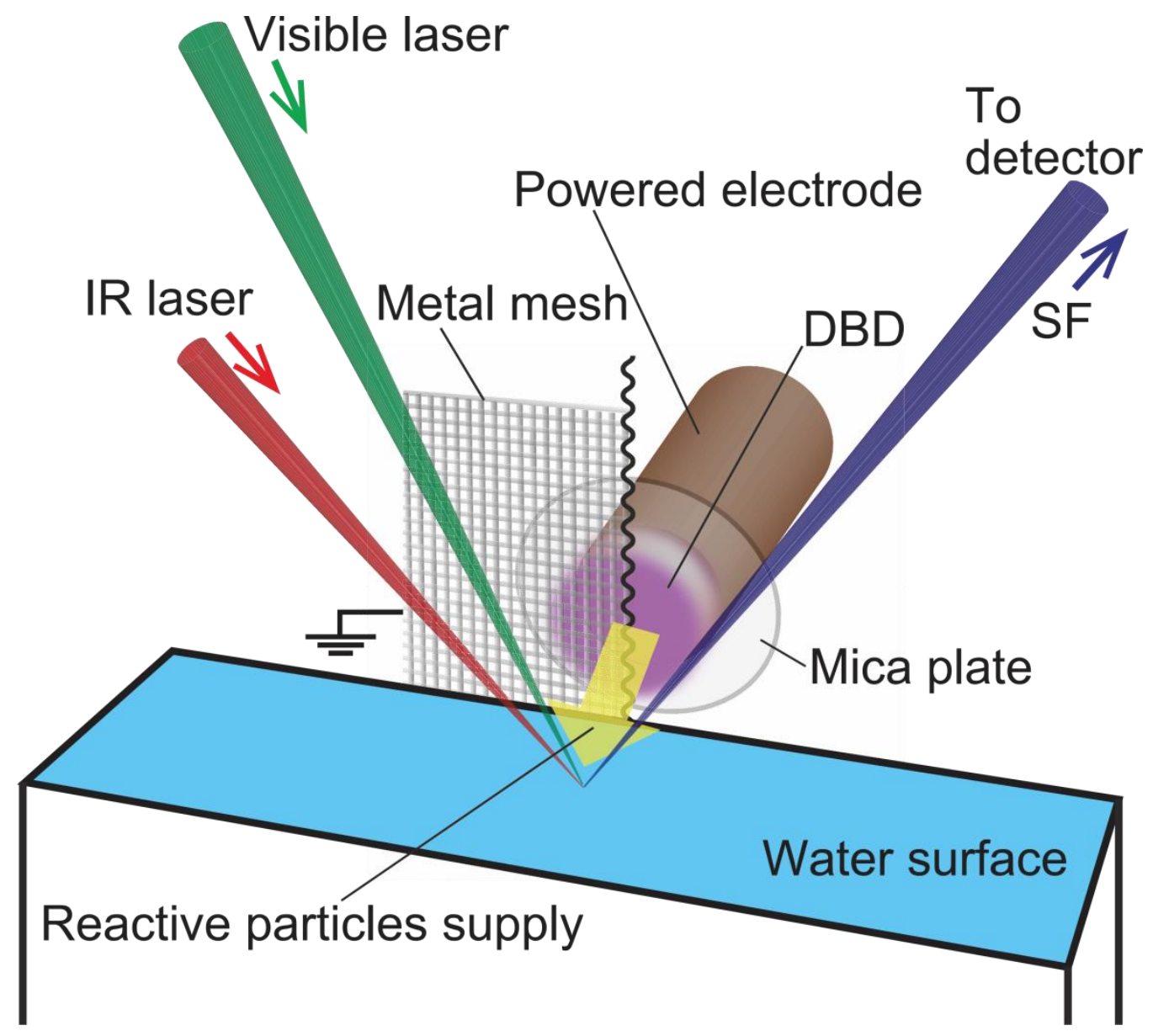

Figure 7: A section of Figure 1 from Kondo et al. ${ }^{238}$ depicting a VSFG experiment on liquid water exposed to a dielectric barrier discharge (DBD). The visible laser is an Nd:YAG device (3-5 ns pulse width and $10 \mathrm{~Hz}$ repetition rate) and the MIR laser $\left(3100-3770 \mathrm{~cm}^{-1}\right)$ an OPO/OPA. The DBD was generated by applying a rectangular voltage to the $\mathrm{HV}$ electrode $\left(10 \mathrm{kV}_{\mathrm{p}-\mathrm{p}}, 4 \mathrm{kHz}\right)$. SF represents the sum-frequency signal. 


\section{Figure captions}

Figure 1. Two-photon excitation and fluorescence (TALIF) schemes for atomic hydrogen, nitrogen and oxygen, and calibration schemes with krypton and xenon. An alternative is also used for Xe, pumping to the $6 p^{\prime}[3 / 2]_{2}$ state at $89162.35 \mathrm{~cm}^{-1}$ (two photons of $224.3 \mathrm{~nm}$ ) and detecting subsequent fluorescence at $834.9 \mathrm{~nm}$ to the $6 \mathrm{~s}^{\prime}[1 / 2]_{1}$ state. All wavelengths are in vacuo. In fs-TALIF, all three spinorbit states of $\mathrm{O}\left({ }^{3} \mathrm{P}\right)$ can be excited simultaneously.

Figure 2: A schematic of the experimental geometry used to make time-resolved studies of atomic absorption within a CAP. (A) The time-resolved absorption of metastable Argon during a single cycle of the HV. In this case the diode laser wavelength is fixed at the line centre of the $\left(1 s_{5} \rightarrow 2 p_{6}\right)$ transition in $\mathrm{Ar}$ at $763.72 \mathrm{~nm}$. (B) Integrated transient absorption as a function of radial position; the maximum absorption is at the centre of the jet and occurs at a radial position of $c a .1 .8 \mathrm{~mm}$. (C) Abel inversion of the data in (B) yield the number densities of metastable argon as function of position with respect to the centre of the CAP jet. The annular structure of the plasma jet is a consequence of the influence of the interior dielectric surface on the discharge..$^{133}$

Figure 3: (a) CRDS spectra of $\mathrm{HO}_{2}$ radicals sampled from a CAP under conditions where the curtain gas is either formed only from $\mathrm{O}_{2}$ or is total devoid of $\mathrm{O}_{2}$ (dashed lines are fits to the data: see [179]). The total pressure in the sample cell is 40 Torr. (b) The variation of $\mathrm{HO}_{2}$ number density as a function of $\mathrm{O}_{2}$ fraction in the curtain gas. Some $\mathrm{HO}_{2}$ is also formed because of the presence of water in the argon carrier gas.

Figure 4: Schematic of a linear optical cavity (with mirror enclosures) consisting of a glass tube surrounded by a water-cooled solenoid. The current is varied between 0 and $400 \mathrm{~A}$ to obtain up to $700 \mathrm{G}$ of magnetic field strength. The cavity transmission can be considered a superposition of the two circular eigenpolarizations; a left $(\mathrm{L})$ and right $(\mathrm{R})$ hand circularly polarised wave. The Wollaston prism (WP) produces two diverging beams, each of which is a linear superposition of the two eigenpolarizations. The lower pane shows the FRS-CRDS spectra of $\mathrm{HO}_{2}$ radicals sampled from a CAP source under varying magnetic field strengths. The total pressure in the sample cell is 30 Torr.

Figure 5: (a) Time-domain representation of a mode-locked laser pulse train and (b) the corresponding frequency-domain picture illustrating the frequency comb structure. In the time domain, pulses with the same intensity profile exhibit a regular separation given by the laser cavity's round-trip time $\tau$. However, due to intracavity dispersion, the electric-field oscillation experiences a pulse-to-pulse phase shift, $\Delta \phi_{\text {ce }}$, with respect to its envelope. The Fourier transform of this series of pulses results an expression for the frequency of every line $m$ of the frequency comb such that $v_{m}=m f_{\text {rep }}+f_{0}$, where $f_{\text {rep }}$ and $f_{0}$ are the laser repetition rate and comb offset frequency, respectively. (c) A near-IR frequency comb spectrum of the $v_{1}+v_{3}$ band of 0.45 Torr of ${ }^{12} \mathrm{C}_{2} \mathrm{H}_{2}$ at $1.52 \mu \mathrm{m}$ over $4 \mathrm{THz}\left(\sim 130 \mathrm{~cm}^{-1}\right)$ within a White cell (3.9 $\mathrm{m}$ total pathlength). The data are extracted using a dual comb interferometric method, and are compared to a simulation from the HITRAN database ${ }^{202}$ : reproduced from Okubo et al. ${ }^{203}$ 
Figure 6: (a) Calculated number densities of major liquid phase components $\left(>10^{14} \mathrm{~cm}^{-3}\right)$ of plasma treated water and. (b) Calculated number densities of some minor liquid-phase components $\left(<10^{13}\right.$ $\mathrm{cm}^{-3}$ ) of plasma treated water both as a function of time after treatment (5000 pulses, $10 \mathrm{~s}$ of a dielectric barrier discharge). Reproduced from Lietz and Kushner. ${ }^{219}$

Figure 7: A section of Figure 1 from Kondo et al. ${ }^{238}$ depicting a VSFG experiment on liquid water exposed to a dielectric barrier discharge (DBD). The visible laser is an Nd:YAG device (3-5 ns pulse width and $10 \mathrm{~Hz}$ repetition rate) and the MIR laser $\left(3100-3770 \mathrm{~cm}^{-1}\right)$ an OPO/OPA. The DBD was generated by applying a rectangular voltage to the $\mathrm{HV}$ electrode $\left(10 \mathrm{kV}_{\mathrm{p}-\mathrm{p}}, 4 \mathrm{kHz}\right)$. SF represents the sum-frequency signal. 


\section{References}

${ }^{1}$ S. Arndt, A. Schmidt, S. Karrer, T. von Woedtke, Comparing two different plasma devices kINPen and Adtec SteriPlas regarding their molecular and cellular effects on wound healing, Clinical Plasma Medicine 9 (2018) 2433.

2 Bardos, L. and H. Barankova (2010). "Cold atmospheric plasma: Sources, processes, and applications." Thin Solid Films 518(23): 6705-6713.

3 J. Golda, J. Held, B. Redeker, M. Konkowski, P. Beijer, A. Sobota, G. Kroesen, N.S.J. Braithwaite, S. Reuter, M.M. Turner, T. Gans, D. O'Connell, V. Schulz-von der Gathen, Concepts and characteristics of the 'COST Reference Microplasma Jet', Journal of Physics D-Applied Physics 49 (2016) 084003

${ }^{4}$ Guo, Y. B. and F. C. N. Hong (2003). "Radio-frequency microdischarge arrays for large-area cold atmospheric plasma generation." Applied Physics Letters 82(3): 337-339.

${ }^{5}$ X. Li, J. Tang, X. Zhan, X. Yuan, Z. Zhao, Y. Yan, Y. Duan, A dielectric-barrier discharge enhanced plasma brush array at atmospheric pressure, Applied Physics Letters 103 (2013) 033519

${ }^{6}$ D. Liu, Z. Zhang, Z. Liu, B. Wang, Q. Li, X. Wang, M.G. Kong, Plasma Jets With Needle-Ring Electrodes: The Insulated Sealing of the Needle and its Effect on the Plasma Characteristics, leee Transactions on Plasma Science 46 (2018) 2942-2948

${ }^{7}$ S. Reuter, T. von Woedtke, K.-D. Weltmann, The kINPen-a review on physics and chemistry of the atmospheric pressure plasma jet and its applications, Journal of Physics D-Applied Physics 51 (2018) 233001 ${ }^{8}$ B.L. Sands, B.N. Ganguly, K. Tachibana, A streamer-like atmospheric pressure plasma jet, Applied Physics Letters 92 (2008) 151503

${ }^{9}$ A. Schutze, J.Y. Jeong, S.E. Babayan, J. Park, G.S. Selwyn, R.F. Hicks, The atmospheric-pressure plasma jet: A review and comparison to other plasma sources, leee Transactions on Plasma Science 26 (1998) 1685-1694.

10 J.L. Walsh, F. Iza, N.B. Janson, V.J. Law, M.G. Kong, Three distinct modes in a cold atmospheric pressure plasma jet, Journal of Physics D-Applied Physics 43 (2010) 075201

11 J.L. Walsh, J.J. Shi, M.G. Kong, Contrasting characteristics of pulsed and sinusoidal cold atmospheric plasma jets, Applied Physics Letters 88 (2006) 171501

12 Q. Xiong, X.P. Lu, K. Ostrikov, Y. Xian, C. Zou, Z. Xiong, Y. Pan, Pulsed dc- and sine-wave-excited cold atmospheric plasma plumes: A comparative analysis, Physics of Plasmas 17 (2010) 043506

${ }^{13}$ Z.-B. Zhang, J. Hopwood, Linear arrays of stable atmospheric pressure microplasmas, Applied Physics Letters 95 (2009) 161502

${ }^{14}$ P.J. Bruggeman, M.J. Kushner, B.R. Locke, J.G.E. Gardeniers, W.G. Graham, D.B. Graves, R. Hofman-Caris, D. Maric, J.P. Reid, E. Ceriani, D.F. Rivas, J.E. Foster, S.C. Garrick, Y. Gorbanev, S. Hamaguchi, F. Iza, H. Jablonowski, E. Klimova, J. Kolb, F. Krcma, P. Lukes, Z. Machala, I. Marinov, D. Mariotti, S.M. Thagard, D. Minakata, E.C. Neyts, J. Pawlat, Z.L. Petrovic, R. Pflieger, S. Reuter, D.C. Schram, S. Schroter, M. Shiraiwa, B. Tarabova, P.A. Tsai, J.R.R. Verlet, T. von Woedtke, K.R. Wilson, K. Yasui, G. Zvereva, Plasma-liquid interactions: a review and roadmap, Plasma Sources Science \& Technology 25 (2016) 053002

${ }^{15}$ E. Stoffels, A.J. Flikweert, W.W. Stoffels, G.M.W. Kroesen, Plasma needle: a non-destructive atmospheric plasma source for fine surface treatment of (bio)materials, Plasma Sources Science \& Technology 11 (2002) 383-388.

${ }^{16}$ E. Stoffels, I.E. Kieft, R.E.J. Sladek, L.J.M. van den Bedem, E.P. van der Laan, M. Steinbuch, Plasma needle for in vivo medical treatment: recent developments and perspectives, Plasma Sources Science \& Technology 15 (2006) S169-S180.

${ }^{17}$ A. Lehmann, A. Rueppell, A. Schindler, I.-M. Zylla, H.J. Seifert, F. Nothdurft, M. Hannig, S. Rupf, Modification of Enamel and Dentin Surfaces by Non-Thermal Atmospheric Plasma, Plasma Processes and Polymers 10 (2013) 262-270.

${ }^{18}$ K. Gupta, B.S. Thomas, S. Kumar, V. Taneja, S. Bhat, Plasma in Dentistry: Novel Technology beyond Lasers, Research Journal of Pharmaceutical Biological and Chemical Sciences 7 (2016) 1902-1910.

${ }^{19}$ M. Gherardi, R. Tonini, V. Colombo, Plasma in Dentistry: Brief History and Current Status, Trends in Biotechnology 36 (2018) 583-585.

${ }^{20}$ S.E. Babayan, J.Y. Jeong, V.J. Tu, J. Park, G.S. Selwyn, R.F. Hicks, Deposition of silicon dioxide films with an atmospheric-pressure plasma jet, Plasma Sources Science \& Technology 7 (1998) 286-288.

${ }^{21}$ J.Y. Jeong, S.E. Babayan, V.J. Tu, J. Park, I. Henins, R.F. Hicks, G.S. Selwyn, Etching materials with an atmospheric-pressure plasma jet, Plasma Sources Science \& Technology 7 (1998) 282-285. 
22 M.C. Kim, S.H. Yang, J.H. Boo, J.G. Han, Surface treatment of metals using an atmospheric pressure plasma jet and their surface characteristics, Surface \& Coatings Technology 174 (2003) 839-844.

${ }^{23}$ U. Lommatzsch, D. Pasedag, A. Baalmann, G. Ellinghorst, H.-E. Wagner, Atmospheric Pressure Plasma Jet Treatment of Polyethylene Surfaces for Adhesion Improvement, Plasma Processes and Polymers 4 (2007) S1041-S1045.

${ }^{24}$ O.V. Penkov, M. Khadem, W.-S. Lim, D.-E. Kim, A review of recent applications of atmospheric pressure plasma jets for materials processing, Journal of Coatings Technology and Research 12 (2015) 225-235.

$25 \mathrm{~J}$. Pawlat, M. Kwiatkowski, P. Terebun, T. Murakami, RF-Powered Atmospheric-Pressure Plasma Jet in Surface Treatment of High-Impact Polystyrene, leee Transactions on Plasma Science 44 (2016) 314-320.

${ }^{26}$ O. Baranov, I. Levchenko, J.M. Bell, J.W.M. Lim, S. Huang, L. Xu, B. Wang, D.U.B. Aussems, S. Xu, K. Bazaka, From nanometre to millimetre: a range of capabilities for plasma-enabled surface functionalization and nanostructuring, Materials Horizons 5 (2018) 765-798

27 J.-H. Tsai, I.C. Cheng, C.-C. Hsu, J.-Z. Chen, DC-pulse atmospheric-pressure plasma jet and dielectric barrier discharge surface treatments on fluorine-doped tin oxide for perovskite solar cell application, Journal of Physics D-Applied Physics 51 (2018) 025502

${ }^{28}$ S. Perni, G. Shama, M.G. Kong, Cold atmospheric plasma disinfection of cut fruit surfaces contaminated with migrating microorganisms, Journal of Food Protection 71 (2008) 1619-1625.

${ }^{29}$ A. Shashurin, M. Keidar, S. Bronnikov, R.A. Jurjus, M.A. Stepp, Living tissue under treatment of cold plasma atmospheric jet, Applied Physics Letters 93 (2008) 181501

${ }^{30}$ E. Stoffels, Y. Sakiyama, D.B. Graves, Cold atmospheric plasma: Charged species and their interactions with cells and tissues, leee Transactions on Plasma Science 36 (2008) 1441-1457.

${ }^{31}$ M. Laroussi, Low-Temperature Plasmas for Medicine?, leee Transactions on Plasma Science 37 (2009) 714 725.

${ }^{32}$ A. Fernandez, A. Thompson, The inactivation of Salmonella by cold atmospheric plasma treatment, Food Research International 45 (2012) 678-684.

${ }^{33}$ G. Isbary, J. Heinlin, T. Shimizu, J.L. Zimmermann, G. Morfill, H.U. Schmidt, R. Monetti, B. Steffes, W. Bunk, Y. Li, T. Klaempfl, S. Karrer, M. Landthaler, W. Stolz, Successful and safe use of 2 min cold atmospheric argon plasma in chronic wounds: results of a randomized controlled trial, British Journal of Dermatology 167 (2012) 404-410.

${ }^{34}$ Y.-F. Li, T. Shimizu, J.L. Zimmermann, G.E. Morfill, Cold Atmospheric Plasma for Surface Disinfection, Plasma Processes and Polymers 9 (2012) 585-589.

${ }^{35}$ T. Maisch, T. Shimizu, Y.-F. Li, J. Heinlin, S. Karrer, G. Morfill, J.L. Zimmermann, Decolonisation of MRSA, Saureus and E-coli by Cold-Atmospheric Plasma Using a Porcine Skin Model In Vitro, Plos One 7 (2012) e34610 ${ }^{36}$ S. Arndt, E. Wacker, Y.-F. Li, T. Shimizu, H.M. Thomas, G.E. Morfill, S. Karrer, J.L. Zimmermann, A.-K. Bosserhoff, Cold atmospheric plasma, a new strategy to induce senescence in melanoma cells, Experimental Dermatology 22 (2013) 284-289.

${ }^{37}$ G. Isbary, T. Shimizu, Y.-F. Li, W. Stolz, H.M. Thomas, G.E. Morfill, J.L. Zimmermann, Cold atmospheric plasma devices for medical issues, Expert Review of Medical Devices 10 (2013) 367-377.

${ }^{38}$ M. Keidar, A. Shashurin, O. Volotskova, M.A. Stepp, P. Srinivasan, A. Sandler, B. Trink, Cold atmospheric plasma in cancer therapy, Physics of Plasmas 20 (2013) 057101

${ }^{39}$ D.B. Graves, Reactive Species from Cold Atmospheric Plasma: Implications for Cancer Therapy, Plasma Processes and Polymers 11 (2014) 1120-1127.

${ }^{40}$ D.B. Graves, Low temperature plasma biomedicine: A tutorial review, Physics of Plasmas 21 (2014) 080901

${ }^{41}$ E.A. Ratovitski, X. Cheng, D. Yan, J.H. Sherman, J. Canady, B. Trink, M. Keidar, Anti-Cancer Therapies of 21st Century: Novel Approach to Treat Human Cancers Using Cold Atmospheric Plasma, Plasma Processes and Polymers 11 (2014) 1128-1137.

42 M. Keidar, Plasma for cancer treatment, Plasma Sources Science \& Technology 24 (2015) 033001

43 J. Gay-Mimbrera, M. Carmen Garcia, B. Isla-Tejera, A. Rodero-Serrano, A. Velez Garcia-Nieto, J. Ruano, Clinical and Biological Principles of Cold Atmospheric Plasma Application in Skin Cancer, Advances in Therapy 33 (2016) 894-909.

${ }^{44}$ C.V. Suschek, C. Oplander, The application of cold atmospheric plasma in medicine: The potential role of nitric oxide in plasma-induced effects, Clinical Plasma Medicine 4 (2016) 1-8.

${ }^{45} \mathrm{H}$. Tanaka, M. Hori, Medical applications of non-thermal atmospheric pressure plasma, Journal of Clinical Biochemistry and Nutrition 60 (2017) 29-32.

${ }^{46}$ D. Guembel, G. Daeschlein, A. Ekkernkamp, A. Kramer, M.B. Stope, Cold atmospheric plasma in orthopaedic and urologic tumor therapy, Gms Hygiene and Infection Control 12 (2017) Doc10 
${ }^{47}$ K.D. Weltmann, T. von Woedtke, Plasma medicine-current state of research and medical application, Plasma Physics and Controlled Fusion 59 (2017) 014031

${ }^{48}$ D.-H. Xu, Q.-J. Cui, Y.-J. Xu, D.-X. Liu, G.-Y. Kong, Plasma Medicine and The Application in Tumor Therapy, Progress in Biochemistry and Biophysics 44 (2017) 279-292.

${ }^{49}$ M. Izadjoo, Z. Sullivan, H. Kim, J. Skiba, Medical applications of cold atmospheric plasma: state of the science, Journal of Wound Care 27 (2018) S4-S10.

${ }^{50}$ L. Nguyen, P. Lu, D. Boehm, P. Bourke, B.F. Gilmore, N.J. Hickok, T.A. Freeman, Cold atmospheric plasma is a viable solution for treating orthopedic infection: a review, Biological Chemistry 400 (2019) 77-86.

${ }^{51}$ C. Schneider, S. Arndt, J.L. Zimmermann, Y. Li, S. Karrer, A.K. Bosserhoff, Cold atmospheric plasma treatment inhibits growth in colorectal cancer cells, Biological Chemistry 400 (2019) 111-122.

52 S. Reuter, H. Tresp, K. Wende, M.U. Hammer, J. Winter, K. Masur, A. Schmidt-Bleker, K.D. Weltmann, From RONS to ROS: Tailoring Plasma Jet Treatment of Skin Cells, leee Transactions on Plasma Science 40 (2012) 2986-2993.

${ }^{53}$ M. Vandamme, E. Robert, S. Lerondel, V. Sarron, D. Ries, S. Dozias, J. Sobilo, D. Gosset, C. Kieda, B. Legrain, J.-M. Pouvesle, A. Le Pape, ROS implication in a new antitumor strategy based on non-thermal plasma, International Journal of Cancer 130 (2012) 2185-2194.

${ }^{54}$ W. Tian, M.J. Kushner, Atmospheric pressure dielectric barrier discharges interacting with liquid covered tissue, Journal of Physics D-Applied Physics 47 (2014) 165201

${ }^{55}$ E.J. Szili, J.-S. Oh, S.-H. Hong, A.H. Hatta, R.D. Short, Probing the transport of plasma-generated RONS in an agarose target as surrogate for real tissue: dependency on time, distance and material composition, Journal of Physics D-Applied Physics 48 (2015) 202001

${ }^{56}$ S.A. Norberg, E. Johnsen, M.J. Kushner, Formation of reactive oxygen and nitrogen species by repetitive negatively pulsed helium atmospheric pressure plasma jets propagating into humid air, Plasma Sources Science \& Technology 24 (2015) 035026

57 S.J. Kim, T.H. Chung, Cold atmospheric plasma jet-generated RONS and their selective effects on normal and carcinoma cells, Scientific Reports 6 (2016) 20332

${ }^{58}$ F. Girard, V. Badets, S. Blanc, K. Gazeli, L. Marlin, L. Authier, P. Svarnas, N. Sojic, F. Clement, S. Arbault, Formation of reactive nitrogen species including peroxynitrite in physiological buffer exposed to cold atmospheric plasma, Rsc Advances 6 (2016) 78457-78467.

59 J. Chauvin, F. Judee, M. Yousfi, P. Vicendo, N. Merbahi, Analysis of reactive oxygen and nitrogen species generated in three liquid media by low temperature helium plasma jet, Scientific Reports 7 (2017) 4562 ${ }^{60}$ A.M. Lietz, M.J. Kushner, Electrode configurations in atmospheric pressure plasma jets: production of reactive species, Plasma Sources Science \& Technology 27 (2018) 105020

${ }^{61}$ Z. Machala, B. Tarabova, D. Sersenova, M. Janda, K. Hensel, Chemical and antibacterial effects of plasma activated water: correlation with gaseous and aqueous reactive oxygen and nitrogen species, plasma sources and air flow conditions, Journal of Physics D-Applied Physics 52 (2019) 034002

${ }^{62}$ S.U. Kalghatgi, G. Fridman, M. Cooper, G. Nagaraj, M. Peddinghaus, M. Balasubramanian, V.N. Vasilets, A.F. Gutsol, A. Fridman, G. Friedman, Mechanism of blood coagulation by nonthermal atmospheric pressure dielectric barrier discharge plasma, leee Transactions on Plasma Science 35 (2007) 1559-1566.

${ }^{63}$ C.Y. Chen, H.W. Fan, S.P. Kuo, J.H. Chang, T. Pedersen, T.J. Mills, C.C. Huang, Blood Clotting by LowTemperature Air Plasma, leee Transactions on Plasma Science 37 (2009) 993-999.

${ }^{64}$ K.P. Arjunan, A.M. Clyne, Hydroxyl Radical and Hydrogen Peroxide are Primarily Responsible for Dielectric Barrier Discharge Plasma-Induced Angiogenesis, Plasma Processes and Polymers 8 (2011) 1154-1164.

65 J. Heinlin, G. Isbary, W. Stolz, G. Morfill, M. Landthaler, T. Shimizu, B. Steffes, T. Nosenko, J.L. Zimmermann, S. Karrer, Plasma applications in medicine with a special focus on dermatology, Journal of the European Academy of Dermatology and Venereology 25 (2011) 1-11.

${ }^{66}$ A.V. Nastuta, I. Topala, C. Grigoras, V. Pohoata, G. Popa, Stimulation of wound healing by helium atmospheric pressure plasma treatment, Journal of Physics D-Applied Physics 44 (2011) 105204

${ }^{67}$ K.P. Arjunan, G. Friedman, A. Fridman, A.M. Clyne, Non-thermal dielectric barrier discharge plasma induces angiogenesis through reactive oxygen species, Journal of the Royal Society Interface 9 (2012) 147-157.

${ }^{68}$ S. Fathollah, S. Mirpour, P. Mansouri, A.R. Dehpour, M. Ghoranneviss, N. Rahimi, Z.S. Naraghi, R. Chalangari, K.M. Chalangari, Investigation on the effects of the atmospheric pressure plasma on wound healing in diabetic rats, Scientific Reports 6 (2016) 19144

${ }^{69}$ S. Bekeschus, J. Bruggemeier, C. Hackbarth, T. von Woedtke, L.I. Partecke, J. van der Linde, Platelets are key in cold physical plasma-facilitated blood coagulation in mice, Clinical Plasma Medicine 7-8 (2017) 58-65. 
${ }^{70} \mathrm{~T}$. Shimizu, Y. Ikehara, Benefits of applying low-temperature plasma treatment to wound care and hemostasis from the viewpoints of physics and pathology, Journal of Physics D-Applied Physics 50 (2017) 503001

${ }^{71}$ S. Bekeschus, J. Bruggemeier, C. Hackbarth, K.D. Weltmann, T. von Woedtke, L.I. Partecke, J. van der Linde, The feed gas composition determines the degree of physical plasma-induced platelet activation for blood coagulation, Plasma Sources Science \& Technology 27 (2018) 034001

72 T. Adachi, H. Tanaka, S. Nonomura, H. Hara, S. Kondo, M. Hod, Plasma-activated medium induces A549 cell injury via a spiral apoptotic cascade involving the mitochondrial-nuclear network, Free Radical Biology and Medicine 79 (2015) 28-44.

${ }^{73}$ M. Dezest, L. Chavatte, M. Bourdens, D. Quinton, M. Camus, L. Garrigues, P. Descargues, S. Arbault, O. Burlet-Schiltz, L. Casteilla, F. Clement, V. Planat, A.L. Bulteau, Mechanistic insights into the impact of Cold Atmospheric Pressure Plasma on human epithelial cell lines, Scientific Reports 7 (2017) 41163

${ }^{74}$ K. Wende, T. von Woedtke, K.D. Weltmann, S. Bekeschus, Chemistry and biochemistry of cold physical plasma derived reactive species in liquids, Biological Chemistry 400 (2019) 19-38.

75 B.L. Sands, B.N. Ganguly, K. Tachibana, Time-Resolved Imaging of "Plasma Bullets" in a Dielectric Capillary Atmospheric Pressure Discharge, leee Transactions on Plasma Science 36 (2008) 956-957.

${ }^{76} \mathrm{~J}$. Jarrige, M. Laroussi, E. Karakas, Formation and dynamics of plasma bullets in a non-thermal plasma jet: influence of the high-voltage parameters on the plume characteristics, Plasma Sources Science and Technology 19 (2010) 065005

77 Q. Xiong, A.Y. Nikiforov, X.P. Lu, C. Leys, High-speed dispersed photographing of an open-air argon plasma plume by a grating-ICCD camera system, Journal of Physics D: Applied Physics 43 (2010) 415201

${ }^{78}$ X. Lu, M. Laroussi, V. Puech, On atmospheric-pressure non-equilibrium plasma jets and plasma bullets, Plasma Sources Science and Technology 21 (2012) 034005

${ }^{79}$ X. Lu, G.V. Naidis, M. Laroussi, K. Ostrikov, Guided ionization waves: Theory and experiments, Physics Reports 540 (2014) 123-166.

${ }^{80}$ M. Boselli, V. Colombo, M. Gherardi, R. Laurita, A. Liguori, P. Sanibondi, E. Simoncelli, A. Stancampiano, Characterization of a Cold Atmospheric Pressure Plasma Jet Device Driven by Nanosecond Voltage Pulses, leee Transactions on Plasma Science 43 (2015) 713-725.

${ }^{81}$ M. Gherardi, N. Puač, D. Marić, A. Stancampiano, G. Malović, V. Colombo, Z.L. Petrović, Practical and theoretical considerations on the use of ICCD imaging for the characterization of non-equilibrium plasmas, Plasma Sources Science and Technology 24 (2015) 064004

82 J. Lei, Y. Geng, K. Liu, W. Zhu, Z. Zheng, H. Hu, Discharge mode transition and temporal-spatial evolution of an air-water plasma jet generated by pulsating DC power, Physics of Plasmas 24 (2017) 123515

83 J. Voráč, P. Synek, V. Procházka, T. Hoder, State-by-state emission spectra fitting for non-equilibrium plasmas: OH spectra of surface barrier discharge at argon/water interface, Journal of Physics D: Applied Physics 50 (2017) 294002

${ }^{84}$ J. Lee, W.J. Nam, S.T. Lee, J.K. Lee, G.S. Yun, Sheath and bulk expansion induced by RF field in atmospheric pressure microwave plasma, Plasma Sources Science and Technology 27 (2018) 075008

85 D. Stone, L.K. Whalley, D.E. Heard, Tropospheric $\mathrm{OH}$ and $\mathrm{HO} 2$ radicals: field measurements and model comparisons, Chemical Society Reviews 41 (2012) 6348-6404.

${ }^{86} \mathrm{R}$. Ono, T. Oda, Measurement of hydroxyl radicals in an atmospheric pressure discharge plasma by using laser-induced fluorescence, leee Transactions on Industry Applications 36 (2000) 82-86.

${ }^{87} \mathrm{G}$. Dilecce, S. De Benedictis, Laser diagnostics of high-pressure discharges: laser induced fluorescence detection of $\mathrm{OH}$ in $\mathrm{He} / \mathrm{Ar}-\mathrm{H} 2 \mathrm{O}$ dielectric barrier discharges, Plasma Physics and Controlled Fusion 53 (2011) 124006

88 S. Kanazawa, H. Kawano, S. Watanabe, T. Furuki, S. Akamine, R. Ichiki, T. Ohkubo, M. Kocik, J. Mizeraczyk, Observation of $\mathrm{OH}$ radicals produced by pulsed discharges on the surface of a liquid, Plasma Sources Science \& Technology 20 (2011) 034010

${ }^{89}$ Y. Nakagawa, R. Ono, T. Oda, Density and temperature measurement of $\mathrm{OH}$ radicals in atmospheric-pressure pulsed corona discharge in humid air, Journal of Applied Physics 110 (2011) 073304

${ }^{90}$ G. Dilecce, P.F. Ambrico, M. Simek, S. De Benedictis, LIF diagnostics of hydroxyl radical in atmospheric pressure He-H2O dielectric barrier discharges, Chemical Physics 398 (2012) 142-147.

91 T. Verreycken, R.M. van der Horst, A. Baede, E.M. Van Veldhuizen, P.J. Bruggeman, Time and spatially resolved LIF of $\mathrm{OH}$ in a plasma filament in atmospheric pressure $\mathrm{He}-\mathrm{H} 2 \mathrm{O}$, Journal of Physics D-Applied Physics 45 (2012) 045205 
92 Q. Xiong, A.Y. Nikiforov, L. Li, P. Vanraes, N. Britun, R. Snyders, X.P. Lu, C. Leys, Absolute OH density determination by laser induced fluorescence spectroscopy in an atmospheric pressure RF plasma jet, European Physical Journal D 66 (2012) 281

93 S. Yonemori, Y. Nakagawa, R. Ono, T. Oda, Measurement of $\mathrm{OH}$ density and air-helium mixture ratio in an atmospheric-pressure helium plasma jet, Journal of Physics D-Applied Physics 45 (2012) 225202

94 L. Li, A. Nikiforov, Q. Xiong, N. Britun, R. Snyders, X. Lu, C. Leys, OH radicals distribution in an Ar-H2O atmospheric plasma jet, Physics of Plasmas 20 (2013) 093502

${ }^{95}$ X. Pei, Y. Lu, S. Wu, Q. Xiong, X. Lu, A study on the temporally and spatially resolved OH radical distribution of a room-temperature atmospheric-pressure plasma jet by laser-induced fluorescence imaging, Plasma Sources Science \& Technology 22 (2013) 025023

${ }^{96}$ T. Verreycken, R. Mensink, R. van der Horst, N. Sadeghi, P.J. Bruggeman, Absolute OH density measurements in the effluent of a cold atmospheric-pressure Ar-H2O RF plasma jet in air, Plasma Sources Science \& Technology 22 (2013) 055014

97 J. Vorac, P. Dvorak, V. Prochazka, J. Ehlbeck, S. Reuter, Measurement of hydroxyl radical (OH) concentration in an argon RF plasma jet by laser-induced fluorescence, Plasma Sources Science \& Technology 22 (2013) 025016

$98 \mathrm{G}$. Dilecce, Optical spectroscopy diagnostics of discharges at atmospheric pressure, Plasma Sources Science \& Technology 23 (2014) 015011

${ }^{99}$ S. Iseni, A. Schmidt-Bleker, J. Winter, K.D. Weltmann, S. Reuter, Atmospheric pressure streamer follows the turbulent argon air boundary in a $\mathrm{MHz}$ argon plasma jet investigated by OH-tracer PLIF spectroscopy, Journal of Physics D-Applied Physics 47 (2014) 152001

100 X.K. Pei, S.Q. Wu, Y.B. Xian, X.P. Lu, Y. Pan, On OH Density of an Atmospheric Pressure Plasma Jet by LaserInduced Fluorescence, leee Transactions on Plasma Science 42 (2014) 1206-1210.

${ }^{101}$ F.P. Sainct, D.A. Lacoste, M.J. Kirkpatrick, E. Odic, C.O. Laux, Temporal evolution of temperature and $\mathrm{OH}$ density produced by nanosecond repetitively pulsed discharges in water vapour at atmospheric pressure, Journal of Physics D-Applied Physics 47 (2014) 075204

102 Y. Teramoto, H.H. Kim, A. Ogata, N. Negishi, Measurement of OH (X-2 Sigma) in immediate vicinity of dielectric surface under pulsed dielectric barrier discharge at atmospheric pressure using two geometries of laser-induced fluorescence, Journal of Applied Physics 115 (2014) 133302

103 T. Verreycken, P.J. Bruggeman, $\mathrm{OH}$ density measurements in nanosecond pulsed discharges in atmospheric pressure N-2-H2O mixtures, Plasma Sources Science \& Technology 23 (2014) 015009

104 T. Verreycken, N. Sadeghi, P.J. Bruggeman, Time-resolved absolute OH density of a nanosecond pulsed discharge in atmospheric pressure $\mathrm{He}-\mathrm{H} 2 \mathrm{O}$ : absolute calibration, collisional quenching and the importance of charged species in $\mathrm{OH}$ production, Plasma Sources Science \& Technology 23 (2014) 045005

105 J. Vorac, A. Obrusnik, V. Prochazka, P. Dvorak, M. Talaba, Spatially resolved measurement of hydroxyl radical $(\mathrm{OH})$ concentration in an argon RF plasma jet by planar laser-induced fluorescence, Plasma Sources Science \& Technology 23 (2014) 025011

${ }^{106} \mathrm{~S}$. Yonemori, R. Ono, Flux of $\mathrm{OH}$ and $\mathrm{O}$ radicals onto a surface by an atmospheric-pressure helium plasma jet measured by laser-induced fluorescence, Journal of Physics D-Applied Physics 47 (2014) 125401

107 T. Yuji, N. Mungkung, H. Kawano, S. Kanazawa, T. Ohkubo, H. Akatsuka, Laser-Induced Fluorescence Detection of $\mathrm{OH}$ Radicals Generated by Atmospheric-Pressure Nonequilibrium DC Pulse Discharge Plasma Jets, leee Transactions on Plasma Science 42 (2014) 960-964.

108 G. Dilecce, L.M. Martini, P. Tosi, M. Scotoni, S. De Benedictis, Laser induced fluorescence in atmospheric pressure discharges, Plasma Sources Science \& Technology 24 (2015) 034007

109 Y.F. Yue, S. Mohades, M. Laroussi, X.P. Lu, Measurements of Plasma-Generated Hydroxyl and Hydrogen Peroxide Concentrations for Plasma Medicine Applications, leee Transactions on Plasma Science 44 (2016) 2754-2758.

${ }^{110}$ L. Gao, C.L. Feng, Z.W. Wang, H.B. Ding, High sensitive and high temporal and spatial resolved image of reactive species in atmospheric pressure surface discharge reactor by laser induced fluorescence, Review of Scientific Instruments 88 (2017) 053107

${ }^{111}$ K. Takeda, K. Ishikawa, H. Tanaka, M. Sekine, M. Hori, Spatial distributions of O, N, NO, OH and vacuum ultraviolet light along gas flow direction in an AC-excited atmospheric pressure Ar plasma jet generated in open air, Journal of Physics D-Applied Physics 50 (2017) 195202

112 Y.F. Yue, X.K. Pei, X.P. Lu, Comparison on the Absolute Concentrations of Hydroxyl and Atomic Oxygen Generated by Five Different Nonequilibrium Atmospheric-Pressure Plasma Jets, leee Transactions on Radiation and Plasma Medical Sciences 1 (2017) 541-549. 
${ }^{113}$ Y.F. Yue, F. Wu, H. Cheng, Y.B. Xian, D.W. Liu, X.P. Lu, X.K. Pei, A donut-shape distribution of OH radicals in atmospheric pressure plasma jets, Journal of Applied Physics 121 (2017) 033302

114 K. Ouaras, L. Magne, S. Pasquiers, P. Tardiveau, P. Jeanney, B. Bournonville, OH density measured by PLIF in a nanosecond atmospheric pressure diffuse discharge in humid air under steep high voltage pulses, Plasma Sources Science \& Technology 27 (2018) 045002

${ }^{115}$ V. Prochazka, Z. Tucekova, P. Dvorak, D. Kovacik, P. Slavicek, A. Zahoranova, J. Vorac, Coplanar surface barrier discharge ignited in water vapor-a selective source of $\mathrm{OH}$ radicals proved by (TA)LIF measurement, Plasma Sources Science \& Technology 27 (2018) 015001

${ }^{116}$ G. Dilecce, P.F. Ambrico, S. De Benedictis, OODR-LIF on N-2(A(3)Sigma(+)(u)) in dielectric barrier discharges, Czechoslovak Journal of Physics 56 (2006) B690-B696.

117 G. Dilecce, P.F. Ambrico, S. De Benedictis, N-2(A (3)Sigma(+)(u)) density measurement in a dielectric barrier discharge in N-2 and N-2 with small 0-2 admixtures, Plasma Sources Science \& Technology 16 (2007) 511-522.

118 P.F. Ambrico, M. Simek, G. Dilecce, S. De Benedictis, On the measurement of N-2(A(3)Sigma(+)(u)) metastable in $\mathrm{N}-2$ surface-dielectric barrier discharge at atmospheric pressure, Plasma Chemistry and Plasma Processing 28 (2008) 299-316.

${ }^{119}$ M. Simek, P.F. Ambrico, S. De Benedictis, G. Dilecce, V. Prukner, J. Schmidt, N-2 (A (3)Sigma(+)(u)) behaviour in a N-2-NO surface dielectric barrier discharge in the modulated ac regime at atmospheric pressure, Journal of Physics D-Applied Physics 43 (2010) 124003

${ }^{120}$ K. Niemi, V. Schulz-von der Gathen and H. F. Döbele, J. Phys. D: Appl. Phys. 34 (2001) 2330-2335

${ }^{121}$ K. Niemi, V. Schulz-von der Gathen and H. F. Döbele, Plasma Sources Sci. Technol. 14 (2005) 375-386

122 J. B. Schmidt, B. L. Sands, W. D. Kulatilaka, S. Roy, J. Scofield and J. R. Gord, Plasma Sources Sci. Technol. 24 (2015) 032004

123 J. B. Schmidt, B. Sands, J. Scofield, J. R. Gord and S. Roy, Plasma Sources Sci. Technol. 26 (2017) 055004

124 J. Kiefer, P. Ewart, Progress in Energy and Combustion Science 37 (2011) 525-564

125 M.J. New, P. Ewart, A. Dreizler, T. Dreier, Appl. Phys. B 65 (1997) 633-637

${ }^{126} \mathrm{~K}$. Nyholm, R. Fritzon, M. Alden, SINGLE-PULSE 2-DIMENSIONAL TEMPERATURE IMAGING IN FLAMES BY DEGENERATE 4-WAVE-MIXING AND POLARIZATION SPECTROSCOPY, Applied Physics B-Lasers and Optics 59 (1994) 37-43.

${ }^{127}$ D. Messina, B. Attal-Tretout, F. Grisch, Study of a non-equilibrium pulsed nanosecond discharge at atmospheric pressure using coherent anti-Stokes Raman scattering, Proceedings of the Combustion Institute 31 (2007) 825-832.

${ }^{128}$ S.J. Pendleton, A. Montello, C. Carter, W. Lempert, M.A. Gundersen, Vibrational and rotational CARS measurements of nitrogen in afterglow of streamer discharge in atmospheric pressure fuel/air mixtures, Journal of Physics D-Applied Physics 45 (2012) 495401

${ }^{129}$ Stauffer H U, Roy S, Schmidt J B, Wrzesinski P J, Gord J R, Two-color vibrational, femtosecond, fully resonant electronically enhanced CARS (FREE-CARS) of gas-phase nitric oxide J. Chem. Phys. 145 (2016) 124308 ${ }^{130}$ A.K. Patnaik, I. Adamovich, J.R. Gord, S. Roy, Recent advances in ultrafast-laser-based spectroscopy and imaging for reacting plasmas and flames, Plasma Sources Science and Technology 26 (2017) 103001

${ }^{131}$ S. Reuter, J.S. Sousa, G.D. Stancu, J.P.H. van Helden, Review on VUV to MIR absorption spectroscopy of atmospheric pressure plasma jets, Plasma Sources Science \& Technology 24 (2015) 054001

${ }^{132}$ G. Pretzler, A NEW METHOD FOR NUMERICAL ABEL-INVERSION, Zeitschrift Fur Naturforschung Section a-a Journal of Physical Sciences 46 (1991) 639-641.

${ }^{133}$ N. Mericam-Bourdet, M. Laroussi, A. Begum, E. Karakas, Experimental investigations of plasma bullets, Journal of Physics D-Applied Physics 42 (2009) 055207

${ }^{134}$ D. Daumont, J. Brion, J. Charbonnier, J. Malicet, OZONE UV SPECTROSCOPY .1. ABSORPTION CROSS-

SECTIONS AT ROOM-TEMPERATURE, Journal of Atmospheric Chemistry 15 (1992) 145-155.

135 J. Malicet, D. Daumont, J. Charbonnier, C. Parisse, A. Chakir, J. Brion, OZONE UV SPECTROSCOPY .2.

ABSORPTION CROSS-SECTIONS AND TEMPERATURE-DEPENDENCE, Journal of Atmospheric Chemistry 21 (1995) 263-273.

${ }^{136}$ C. Parisse, J. Brion, J. Malicet, UV absorption spectrum of ozone: Structure analysis and study of the isotope effect in the Hartley system, Chemical Physics Letters 248 (1996) 31-36.

${ }^{137}$ M. Petersen, J. Viallon, P. Moussay, R.I. Wielgosz, Relative measurements of ozone absorption crosssections at three wavelengths in the Hartley band using a well-defined UV laser beam, Journal of Geophysical Research-Atmospheres 117 (2012) D05301

138 J. Winter, M. Dunnbier, A. Schmidt-Bleker, A. Meshchanov, S. Reuter, K.D. Weltmann, Aspects of UVabsorption spectroscopy on ozone in effluents of plasma jets operated in air, Journal of Physics D-Applied Physics 45 (2012) 385201 
${ }^{139}$ F. Hegeler, H. Akiyama, Spatial and temporal distributions of ozone after a wire-to-plate streamer discharge, leee Transactions on Plasma Science 25 (1997) 1158-1165.

140 J.Y. Jeong, J. Park, I. Henins, S.E. Babayan, V.J. Tu, G.S. Selwyn, G. Ding, R.F. Hicks, Reaction chemistry in the afterglow of an oxygen-helium, atmospheric-pressure plasma, Journal of Physical Chemistry A 104 (2000) 8027-8032.

141 J. Park, I. Henins, H.W. Herrmann, G.S. Selwyn, J.Y. Jeong, R.F. Hicks, D. Shim, C.S. Chang, An atmospheric pressure plasma source, Applied Physics Letters 76 (2000) 288-290.

142 Y. Kim, J. Park, L.A. Rosocha, H.L. Teslow, H.W. Herrmann, Measurements of dioxygen fluoride (O2F) in an atmospheric pressure plasma jet, Applied Physics Letters 87 (2005) 011502

143 R. Ono, T. Oda, Dynamics of ozone and $\mathrm{OH}$ radicals generated by pulsed corona discharge in humid-air flow reactor measured by laser spectroscopy, Journal of Applied Physics 93 (2003) 5876-5882.

144 R. Ono, T. Oda, Spatial distribution of ozone density in pulsed corona discharges observed by twodimensional laser absorption method, Journal of Physics D-Applied Physics 37 (2004) 730-735.

${ }^{145}$ R. Ono, T. Oda, Ozone production process in pulsed positive dielectric barrier discharge, Journal of Physics D-Applied Physics 40 (2007) 176-182.

${ }^{146}$ A. Wijaikhum, D. Schroder, S. Schroter, A.R. Gibson, K. Niemi, J. Friderich, A. Greb, V. Schulz-von der Gathen, D. O'Connell, T. Gans, Absolute ozone densities in a radio-frequency driven atmospheric pressure plasma using two-beam UV-LED absorption spectroscopy and numerical simulations, Plasma Sources Science \& Technology 26 (2017) 115004

${ }^{147}$ K. Niemi, D. O'Connell, N. de Oliveira, D. Joyeux, L. Nahon, J. P. Booth and T. Gans Applied Physics Letters 103, 034102 (2013) 034102

148 J. Dedrick, S. Schröter, K. Niemi, A. Wijaikhum, E. Wagenaars, N. de Oliveira, L. Nahon, J.P. Booth, D. O'Connell, T. Gans, Controlled production of atomic oxygen and nitrogen in a pulsed radio-frequency atmospheric-pressure plasma, Journal of Physics D: Applied Physics 50 (2017) 455204

${ }^{149}$ A.V. Pipa, S. Reuter, R. Foest, K.D. Weltmann, Controlling the NO production of an atmospheric pressure plasma jet, Journal of Physics D-Applied Physics 45 (2012) 085201

${ }^{150} \mathrm{C}$. Douat, S. Hubner, R. Engeln, J. Benedikt, Production of nitric/nitrous oxide by an atmospheric pressure plasma jet, Plasma Sources Science \& Technology 25 (2016) 025027

${ }^{151}$ M.S. Simeni, C.O. Laux, G.D. Stancu, High-spatial resolution measurements of NO density and temperature by Mid-IR QCLAS in open-air confined plasmas, Journal of Physics D-Applied Physics 50 (2017) 274004

${ }^{152}$ G. Berden, R. Peeters, G. Meijer, - Cavity ring-down spectroscopy: Experimental schemes and applications, International Reviews in Physical Chemistry, 19 (2000) 607.

${ }^{153}$ M. Mazurenka, A.J. Orr-Ewing, R. Peverall, G.A.D. Ritchie, - Cavity ring-down and cavity enhanced spectroscopy using diode lasers, Annual Reports on the Progress of Chemistry - Section C 101 (2005) 142.

154 D. Romanini, A.A. Kachanov, F. Stoeckel, - Diode laser cavity ring down spectroscopy, Chem. Phys. Letts 270 (1997) 545.

${ }^{155}$ M. Gupta, T. Owano, D.S. Baer, A. O'Keefe, S. Williams, Quantitative determination of singlet oxygen density and temperature for Oxygen-lodine Laser Applications, Chemical Physics Letters 400 (2004) 42-46.

${ }^{156}$ S. Williams, M. Gupta, T. Owano, D.S. Baer, A. O'Keefe, D.R. Yarkony, S. Matsika, Quantitative detection of singlet O-2 by cavity-enhanced absorption, Optics Letters 29 (2004) 1066-1068.

157 G. Hancock, R. Peverall, G.A.D. Ritchie, L.J. Thornton, The number density of ground state atomic oxygen $(\mathrm{O}(\mathrm{P}-3(2)))$ measured in an inductively coupled plasma chamber by cavity enhanced absorption, Journal of Physics D-Applied Physics 40 (2007) 4515-4518.

${ }^{158}$ R. Engeln, K.G.Y. Letourneur, M.G.H. Boogaarts, M.C.M. van de Sanden, D.C. Schram, Detection of CH in an expanding argon/acetylene plasma using cavity ring down absorption spectroscopy, Chemical Physics Letters 310 (1999) 405-410.

159 J.B. Wills, J.A. Smith, W.E. Boxford, J.M.F. Elks, M.N.R. Ashfold, A.J. Orr-Ewing, Measurements of C-2 and CH concentrations and temperatures in a dc arc jet using cavity ring-down spectroscopy, Journal of Applied Physics 92 (2002) 4213-4222.

160 B. Bakowski, G. Hancock, R. Peverall, G.A.D. Ritchie, L.J. Thornton, Characterization of an inductively coupled N-2 plasma using sensitive diode laser spectroscopy, Journal of Physics D-Applied Physics 37 (2004) 2064-2072.

161 P.J. van den Oever, J.H. van Helden, C.C.H. Lamers, R. Engeln, D.C. Schram, M.C.M. van de Sanden, W.M.M. Kessels, Density and production of $\mathrm{NH}$ and NH2 in an Ar-NH3 expanding plasma jet, Journal of Applied Physics 98 (2005) 093301 
162 G. Hancock, R. Peverall, G.A.D. Ritchie, L.J. Thornton, Absolute number densities of vibrationally excited N-2 (A(3)Sigma(+)(u)) produced in a low pressure rf plasma, Journal of Physics D-Applied Physics 39 (2006) 18461852.

163 P.J. van den Oever, J.H. van Helden, J.L. van Hemmen, R. Engeln, D.C. Schram, M.C.M. van de Sanden, W.M.M. Kessels, $\mathrm{N}, \mathrm{NH}$, and $\mathrm{NH} 2$ radical densities in a remote $\mathrm{Ar}-\mathrm{NH} 3-\mathrm{SiH} 4$ plasma and their role in silicon nitride deposition, Journal of Applied Physics 100 (2006) 093303

164 J.H. van Helden, P.J. van den Oever, W.M.M. Kessels, M. de Sanden, D.C. Schram, R. Engeln, Production mechanisms of $\mathrm{NH}$ and $\mathrm{NH}_{2}$ radicals in N-2-H-2 plasmas, Journal of Physical Chemistry A 111 (2007) 1146011472.

165 J. Ma, J.C. Richley, M.N.R. Ashfold, Y.A. Mankelevich, Probing the plasma chemistry in a microwave reactor used for diamond chemical vapor deposition by cavity ring down spectroscopy, Journal of Applied Physics 104 (2008) 103305

166 J.C. Richley, O.J.L. Fox, M.N.R. Ashfold, Y.A. Mankelevich, Combined experimental and modeling studies of microwave activated $\mathrm{CH} 4 / \mathrm{H}-2 /$ Ar plasmas for microcrystalline, nanocrystalline, and ultrananocrystalline diamond deposition, Journal of Applied Physics 109 (2011) 063307

${ }^{167}$ B.S. Truscott, M.W. Kelly, K.J. Potter, M. Johnson, M.N.R. Ashfold, Y.A. Mankelevich, Microwave PlasmaActivated Chemical Vapor Deposition of Nitrogen-Doped Diamond. I. N-2/H-2 and NH3/H-2 Plasmas, Journal of Physical Chemistry A 119 (2015) 12962-12976.

168 B.S. Truscott, M.W. Kelly, K.J. Potter, M.N.R. Ashfold, Y.A. Mankelevich, Microwave Plasma-Activated Chemical Vapor Deposition of Nitrogen-Doped Diamond. II: CH4/N-2/H-2 Plasmas, Journal of Physical Chemistry A 120 (2016) 8537-8549.

${ }^{169} \mathrm{C}$. Wang, N. Srivastava, $\mathrm{OH}$ number densities and plasma jet behavior in atmospheric microwave plasma jets operating with different plasma gases (Ar, Ar/N-2, and Ar/O-2), European Physical Journal D 60 (2010) 465477.

${ }^{170} \mathrm{~N}$. Srivastava, C.J. Wang, Effects of water addition on $\mathrm{OH}$ radical generation and plasma properties in an atmospheric argon microwave plasma jet, Journal of Applied Physics 110 (2011) 053304

${ }^{171}$ N. Srivastava, C.J. Wang, Determination of $\mathrm{OH}$ Radicals in an Atmospheric Pressure Helium Microwave Plasma Jet, leee Transactions on Plasma Science 39 (2011) 918-924.

172 C. O. Laux, T. G. Spence, C. H. Kruger and R. N. Zare, Plasma Sources Sci. Technol. 12 (2003) 125-138

173 G. D. Stancu, M. Janda, F. Kaddouri, D. A. Lacoste, and C. O. Laux, J. Phys. Chem. A, Vol. 114 (2010), 201-208

174 J.S. Sousa, K. Niemi, L.J. Cox, Q.T. Algwari, T. Gans, D. O'Connell, Cold atmospheric pressure plasma jets as sources of singlet delta oxygen for biomedical applications, Journal of Applied Physics 109 (2011) 123302 ${ }^{175} \mathrm{Y}$. Inoue, R. Ono, Measurement of singlet delta oxygen in an atmospheric-pressure helium-oxygen plasma jet, Journal of Physics D-Applied Physics 50 (2017) 214001

${ }^{176}$ M. Gianella, S. Reuter, A.L. Aguila, G.A.D. Ritchie, J.P.H. van Helden, Detection of HO2 in an atmospheric pressure plasma jet using optical feedback cavity-enhanced absorption spectroscopy, New Journal of Physics 18 (2016) 113027

177 J. Morville, S. Kassi, M. Chenevier, D. Romanini, Appl. Phys. B 80 (2005) 1027-1038

178 M. Dünnbier, A. Schmidt-Bleker, J. Winter, M. Wolfram, R. Hippler, K. D. Weltmann and S. Reuter, J. Phys. D: Appl. Phys. 46 (2013) 435203

${ }^{179}$ M. Gianella, S. Reuter, S.A. Press, A. Schmidt-Bleker, J.H. van Helden, G.A.D. Ritchie, HO2 reaction kinetics in an atmospheric pressure plasma jet determined by cavity ring-down spectroscopy, Plasma Sources Science $\&$ Technology 27 (2018) 095013

${ }^{180}$ G. Litfin, C.R. Pollock, R.F. Curl, F.K. Tittel, SENSITIVITY ENHANCEMENT OF LASER-ABSORPTION

SPECTROSCOPY BY MAGNETIC ROTATION EFFECT, Journal of Chemical Physics 72 (1980) 6602-6605.

${ }^{181}$ B. Brumfield, W.T. Sun, Y. Wang, Y.G. Ju, G. Wysocki, Dual modulation Faraday rotation spectroscopy of $\mathrm{HO}_{2}$ in a flow reactor, Optics Letters 39 (2014) 1783-1786.

182 R. Engeln, G. Berden, E. vandenBerg, G. Meijer, Polarization dependent cavity ring down spectroscopy, Journal of Chemical Physics 107 (1997) 4458-4467.

${ }^{183}$ M. Gianella, T.H.P. Pinto, X. Wu, G.A.D. Ritchie, Intracavity Faraday modulation spectroscopy (INFAMOS): A tool for radical detection, Journal of Chemical Physics 147 (2017) 054201

${ }^{184}$ S. A. Press, cavity ring-down studies of plasmas, part II master's thesis, University of Oxford, (2018).

${ }^{185}$ S. A. Diddams, D.J. Jones, J. Ye, S.T. Cundiff, J.L. Hall, J.K. Ranka, R.S. Windeler, R. Holzwarth, T. Udem, T.W. Hansch, Direct link between microwave and optical frequencies with a $300 \mathrm{THz}$ femtosecond laser comb, Physical Review Letters 84 (2000) 5102-5105.

${ }^{186}$ R. Holzwarth, T. Udem, T.W. Hansch, J.C. Knight, W.J. Wadsworth, P.S.J. Russell, Optical frequency synthesizer for precision spectroscopy, Physical Review Letters 85 (2000) 2264-2267. 
${ }^{187}$ T. Udem, R. Holzwarth, T.W. Hansch, Optical frequency metrology, Nature 416 (2002) 233-237.

${ }^{188}$ S.T. Cundiff, J. Ye, Colloquium: Femtosecond optical frequency combs, Reviews of Modern Physics 75 (2003) $325-342$

189 J. Ye, S. T. Cundiff (eds.), Femtosecond Optical Frequency Comb: Principle, Operation, and Applications (Springer, Berlin, 2004).

${ }^{190}$ T.W. Hansch, Nobel Lecture: Passion for precision, Reviews of Modern Physics 78 (2006) 1297-1309.

191 J.L. Hall, Nobel Lecture: Defining and measuring optical frequencies, Reviews of Modern Physics 78 (2006) 1279-1295.

${ }^{192}$ T. Udem, J. Reichert, R. Holzwarth, T.W. Hansch, Absolute optical frequency measurement of the cesium D1 line with a mode-locked laser, Physical Review Letters 82 (1999) 3568-3571.

${ }^{193}$ A. Marian, M.C. Stowe, J.R. Lawall, D. Felinto, J. Ye, United time-frequency spectroscopy for dynamics and global structure, Science 306 (2004) 2063-2068.

${ }^{194}$ M.J. Thorpe, J. Ye, Cavity-enhanced direct frequency comb spectroscopy, Applied Physics B-Lasers and Optics 91 (2008) 397-414.

${ }^{195}$ F. Adler, M.J. Thorpe, K.C. Cossel, J. Ye, Cavity-enhanced direct frequency comb spectroscopy: technology and applications, Ann. Rev. Anal. Chem. (3)3, eds. E.S. Yeung, R.N. Zare (2010). 175 - 205

${ }^{196}$ A. Foltynowicz, P. Maslowski, T. Ban, F. Adler, K.C. Cossel, T.C. Briles, J. Ye, Optical frequency comb spectroscopy, Faraday Discussions 150 (2011) 23-31.

${ }^{197}$ T.R. Schibli, I. Hartl, D.C. Yost, M.J. Martin, A. Marcinkevicius, M.E. Fermann, J. Ye, Optical frequency comb with submillihertz linewidth and more than $10 \mathrm{~W}$ average power, Nature Photonics 2 (2008) 355-359.

${ }^{198}$ M.J. Thorpe, K.D. Moll, R.J. Jones, B. Safdi, J. Ye, Broadband cavity ringdown spectroscopy for sensitive and rapid molecular detection, Science 311 (2006) 1595-1599.

${ }^{199}$ P. Maslowski et al. 2014 Cavity-Enhanced Direct Frequency Comb Spectroscopy, Chapter 8 in G. Gagliardi, H.-P. Loock (eds.), Cavity-Enhanced Spectroscopy and Sensing, Springer Series in Optical Sciences 179, DOI 10.1007/978-3-642-40003-2_8.

${ }^{200}$ M.L. Weichman, P.B. Changala, J. Ye, Z.J. Chen, M. Yan, N. Picque, Broadband molecular spectroscopy with optical frequency combs, Journal of Molecular Spectroscopy 355 (2019) 66-78.

${ }^{201}$ N. Picqué, T.W. Hänsch, Frequency comb spectroscopy, Nature Photonics 13 (2019) 146-157.

202 I.E. Gordon, L.S. Rothman, C. Hill, R.V. Kochanov, Y. Tan, P.F. Bernath, M. Birk, V. Boudon, A. Campargue, K.V. Chance, B.J. Drouin, J.M. Flaud, R.R. Gamache, J.T. Hodges, D. Jacquemart, V.I. Perevalov, A. Perrin, K.P. Shine, M.A.H. Smith, J. Tennyson, G.C. Toon, H. Tran, V.G. Tyuterev, A. Barbe, A.G. Csaszar, V.M. Devi, T. Furtenbacher, J.J. Harrison, J.M. Hartmann, A. Jolly, T.J. Johnson, T. Karman, I. Kleiner, A.A. Kyuberis, J. Loos, O.M. Lyulin, S.T. Massie, S.N. Mikhailenko, N. Moazzen-Ahmadi, H.S.P. Muller, O.V. Naumenko, A.V. Nikitin, O.L. Polyansky, M. Rey, M. Rotger, S.W. Sharpe, K. Sung, E. Starikova, S.A. Tashkun, J. Vander Auwera, G. Wagner, J. Wilzewski, P. Wcislo, S. Yu, E.J. Zak, The HITRAN2016 molecular spectroscopic database, Journal of Quantitative Spectroscopy \& Radiative Transfer 203 (2017) 3-69.

${ }^{203}$ S. Okubo, K. Iwakuni, H. Inaba, K. Hosaka, A. Onae, H. Sasada, F.-L. Hong, Ultra-broadband dual-comb spectroscopy across 1.0-1.9 $\mu \mathrm{m}$, Applied Physics Express 8 (2015) 082402

${ }^{204}$ M. Golkowski, C. Golkowski, J. Leszczynski, S.R. Plimpton, P. Maslowski, A. Foltynowicz, J. Ye, B. McCollister, Hydrogen-Peroxide-Enhanced Nonthermal Plasma Effluent for Biomedical Applications, leee Transactions on Plasma Science 40 (2012) 1984-1991.

${ }^{205}$ M.J. Thorpe, F. Adler, K.C. Cossel, M.H.G. de Miranda, J. Ye, Tomography of a supersonically cooled molecular jet using cavity-enhanced direct frequency comb spectroscopy, Chemical Physics Letters 468 (2009) 1-8.

${ }^{206}$ B. Bernhardt, A. Ozawa, P. Jacquet, M. Jacquey, Y. Kobayashi, T. Udem, R. Holzwarth, G. Guelachvili, T.W. Hansch, N. Picque, Cavity-enhanced dual-comb spectroscopy, Nature Photonics 4 (2010) 55-57.

${ }^{207}$ K.C. Cossel, F. Adler, K.A. Bertness, M.J. Thorpe, J. Feng, M.W. Raynor, J. Ye, Analysis of trace impurities in semiconductor gas via cavity-enhanced direct frequency comb spectroscopy, Applied Physics B-Lasers and Optics 100 (2010) 917-924.

${ }^{208}$ A. Foltynowicz, T. Ban, P. Maslowski, F. Adler, J. Ye, Quantum-noise-limited optical frequency comb spectroscopy, Phys Rev Lett 107 (2011) 233002.

${ }^{209}$ R. Grilli, G. Mejean, C. Abd Alrahman, I. Ventrillard, S. Kassi, D. Romanini, Cavity-enhanced multiplexed comb spectroscopy down to the photon shot noise, Physical Review A 85 (2012) 051804

${ }^{210}$ A. Foltynowicz, P. Maslowski, A.J. Fleisher, B.J. Bjork, J. Ye, Cavity-enhanced optical frequency comb spectroscopy in the mid-infrared application to trace detection of hydrogen peroxide, Applied Physics B-Lasers and Optics 110 (2013) 163-175. 
${ }^{211}$ A. Khodabakhsh, A.C. Johansson, A. Foltynowicz, Noise-immune cavity-enhanced optical frequency comb spectroscopy: a sensitive technique for high-resolution broadband molecular detection, Applied Physics BLasers and Optics 119 (2015) 87-96.

212 B. Spaun, P.B. Changala, D. Patterson, B.J. Bjork, O.H. Heckl, J.M. Doyle, J. Ye, Continuous probing of cold complex molecules with infrared frequency comb spectroscopy, Nature 533 (2016) 517.

213 L. Rutkowski, J. Morville, Continuous Vernier filtering of an optical frequency comb for broadband cavityenhanced molecular spectroscopy, Journal of Quantitative Spectroscopy \& Radiative Transfer 187 (2017) 204214.

${ }^{214}$ N. Hoghooghi, R.J. Wright, A.S. Makowiecki, W.C. Swann, E.M. Waxman, I. Coddington, G.B. Rieker, Broadband coherent cavity-enhanced dual-comb spectroscopy, Optica 6 (2019) 28-33.

${ }^{215}$ A.C. Johansson, J. Westberg, G. Wysocki, A. Foltynowicz, Optical frequency comb Faraday rotation spectroscopy, Applied Physics B-Lasers and Optics 124 (2018) 79

${ }^{216}$ M.A.R. Reber, Y. Chen, T.K. Allison, Cavity-enhanced ultrafast spectroscopy: ultrafast meets ultrasensitive, Optica 3 (2016) 311-317.

${ }^{217}$ C.A.J. van Gils, S. Hofmann, B. Boekema, R. Brandenburg, P.J. Bruggeman, Mechanisms of bacterial inactivation in the liquid phase induced by a remote RF cold atmospheric pressure plasma jet, Journal of Physics D-Applied Physics 46 (2013) 175203

${ }^{218}$ W. Van Boxem, J. Van der Paal, Y. Gorbanev, S. Vanuytsel, E. Smits, S. Dewilde, A. Bogaerts, Anti-cancer capacity of plasma-treated PBS: effect of chemical composition on cancer cell cytotoxicity, Scientific Reports 7 (2017) 16478

${ }^{219}$ A M Lietz and M J Kushner, J. Phys. D: Appl. Phys. 49 (2016) 425204

220 C.C.W. Verlackt, W. Van Boxem, A. Bogaerts, Transport and accumulation of plasma generated species in aqueous solution, Physical Chemistry Chemical Physics 20 (2018) 6845-6859.

${ }^{221}$ D. Levko, A. Sharma, L.L. Raja, Kinetic modeling of streamer penetration into de-ionized water, Physics of Plasmas 25 (2018) 033515

222 P. Attri, M. Yusupov, J.H. Park, L.P. Lingamdinne, J.R. Koduru, M. Shiratani, E.H. Choi, A. Bogaerts, Sci. Rep. 6 (2016) 34419.

${ }^{223}$ M.C. García, M. Mora, D. Esquivel, J.E. Foster, A. Rodero, C. Jimenez-Sanchidrian, F.J. Romero-Salguero, Chemosphere 180 (2017) 239.

${ }^{224}$ M. Hayyan, M.A. Hashim, I.M. Al Nashef, Chem. Rev. 116 (2016) 3029.

225 P. Attri, Y.H. Kim, D.H. Park, J.H. Park, Y.J. Hong, H.S. Uhm, K.-N. Kim, A. Fridman, E.H. Choi, Sci. Rep. 5 (2015) 9332.

${ }^{226}$ K. Chandrasekara Pillai, T.O. Kwon, I.S. Moon, Appl. Catal., B 91 (2009) 319.

${ }^{227}$ E.J. Baek, H.M. Joh, S.J. Kim, T.H. Chung, Effects of the electrical parameters and gas flow rate on the generation of reactive species in liquids exposed to atmospheric pressure plasma jets, Physics of Plasmas 23 (2016) 073515

${ }^{228}$ P. Rumbach, D.M. Bartels, R.M. Sankaran, D.B. Go, The effect of air on solvated electron chemistry at a plasma/liquid interface, Journal of Physics D: Applied Physics 48 (2015) 424001

229 P. Rumbach, D.M. Bartels, R.M. Sankaran, D.B. Go, The solvation of electrons by an atmospheric-pressure plasma, Nat Commun 6 (2015) 7248.

${ }^{230}$ A.C.R. Pipino, Ultrasensitive surface spectroscopy with a miniature optical resonator, Physical Review Letters 83 (1999) 3093-3096.

231 A.C.R. Pipino, Monolithic folded resonator for evanescent wave cavity ringdown spectroscopy, Applied Optics 39 (2000) 1449-1453.

${ }^{232}$ L. van der Sneppen, F. Ariese, C. Gooijer, W. Ubachs, Liquid-Phase and Evanescent-Wave Cavity Ring-Down Spectroscopy in Analytical Chemistry, Annual Review of Analytical Chemistry 2 (2009) 13-35.

${ }^{233}$ L. van der Sneppen, G. Hancock, C. Kaminski, T. Laurila, S.R. Mackenzie, S.R.T. Neil, R. Peverall, G.A.D.

Ritchie, M. Schnippering, P.R. Unwin, Following interfacial kinetics in real time using broadband evanescent wave cavity-enhanced absorption spectroscopy: a comparison of light-emitting diodes and supercontinuum sources, Analyst 135 (2010) 133-139.

${ }^{234}$ M. Schnippering, S.R.T. Neil, S.R. Mackenzie, P.R. Unwin, Evanescent wave cavity-based spectroscopic techniques as probes of interfacial processes, Chemical Society Reviews 40 (2011) 207-220.

${ }^{235}$ A.C.R. Pipino, J.P.M. Hoefnagels, N. Watanabe, Absolute surface coverage measurement using a vibrational overtone, Journal of Chemical Physics 120 (2004) 2879-2888.

${ }^{236}$ I.M.P. Aarts, A.C.R. Pipino, M. de Sanden, W.M.M. Kessels, Absolute in situ measurement of surface dangling bonds during a-Si : H growth, Applied Physics Letters 90 (2007) 161918 
${ }^{237}$ F.J.J. Peeters, J. Zheng, I.M.P. Aarts, A.C.R. Pipino, W.M.M. Kessels, M.C.M. van de Sanden, Atomic hydrogen induced defect kinetics in amorphous silicon, Journal of Vacuum Science \& Technology A 35 (2017) 05c307

${ }^{238}$ T. Kondo, M. Tsumaki, W.A. Diño, T. Ito, Influence of reactive gas-phase species on the structure of an air/water interface, Journal of Physics D: Applied Physics 50 (2017) 244002.

${ }^{239}$ C. D. Bain, P. B. Davies, T. H. Ong, R. N. Ward, M. A. Brown, Quantitative analysis of monolayer composition by sum-frequency vibrational spectroscopy, Langmuir 7, (1991) 1563-1566.

${ }^{240}$ G.R. Bell, C.D. Bain, R. N. Ward, Sum-frequency vibrational spectroscopy of soluble surfactants at the air/water interface, J. Chem. Soc., Faraday Trans., 1996,92(4), 515-523

${ }^{241}$ C.L. Hawkins, M.J. Davies, Detection and characterisation of radicals in biological materials using EPR methodology, Biochimica Et Biophysica Acta-General Subjects 1840 (2014) 708-721.

242 M.J. Davies, Detection and characterisation of radicals using electron paramagnetic resonance (EPR) spin trapping and related methods, Methods 109 (2016) 21-30.

243 M.M. Roessler, E. Salvadori, Principles and applications of EPR spectroscopy in the chemical sciences, Chemical Society Reviews 47 (2018) 2534-2553.

244 T. Takamatsu, K. Uehara, Y. Sasaki, H. Miyahara, Y. Matsumura, A. Iwasawa, N. Ito, T. Azuma, M. Kohno, A. Okino, Investigation of reactive species using various gas plasmas, Rsc Advances 4 (2014) 39901-39905.

${ }^{245}$ H. Uchiyama, Q.L. Zhao, M.A. Hassan, G. Andocs, N. Nojima, K. Takeda, K. Ishikawa, M. Hori, T. Kondo, EPRSpin Trapping and Flow Cytometric Studies of Free Radicals Generated Using Cold Atmospheric Argon Plasma and X-Ray Irradiation in Aqueous Solutions and Intracellular Milieu, Plos One 10 (2015) e0136956

${ }^{246}$ M.U. Rehman, P. Jawaid, H. Uchiyama, T. Kondo, Comparison of free radicals formation induced by cold atmospheric plasma, ultrasound, and ionizing radiation, Archives of Biochemistry and Biophysics 605 (2016) 19-25.

${ }^{247}$ Y. Gorbanev, D. O'Connell, V. Chechik, Non-Thermal Plasma in Contact with Water: The Origin of Species, Chemistry-a European Journal 22 (2016) 3496-3505.

${ }^{248}$ Y. Gorbanev, N. Stehling, D. O'Connell, V. Chechik, Reactions of nitroxide radicals in aqueous solutions exposed to non-thermal plasma: limitations of spin trapping of the plasma induced species, Plasma Sources Science \& Technology 25 (2016) 055017

249 Q. Zhang, P. Sun, H.Q. Feng, R.X. Wang, Y.D. Liang, W.D. Zhu, K.H. Becker, J. Zhang, J. Fang, Assessment of the roles of various inactivation agents in an argon-based direct current atmospheric pressure cold plasma jet, Journal of Applied Physics 111 (2012) 123305

250 N. Kurake, H. Tanaka, K. Ishikawa, K. Takeda, H. Hashizume, K. Nakamura, H. Kajiyama, T. Kondo, F. Kikkawa, M. Mizuno, M. Hori, Effects of center dot $\mathrm{OH}$ and center dot $\mathrm{NO}$ radicals in the aqueous phase on $\mathrm{H} 2 \mathrm{O} 2$ and NO2- generated in plasma-activated medium, Journal of Physics D-Applied Physics 50 (2017) 155202

${ }^{251}$ H.Q. Feng, R.X. Wang, P. Sun, H.Y. Wu, Q. Liu, J. Fang, W.D. Zhu, F.T. Li, J. Zhang, A study of eukaryotic response mechanisms to atmospheric pressure cold plasma by using Saccharomyces cerevisiae single gene mutants, Applied Physics Letters 97 (2010) 131501

252 P. Sun, Y. Sun, H.Y. Wu, W.D. Zhu, J.L. Lopez, W. Liu, J. Zhang, R.Y. Li, J. Fang, Atmospheric pressure cold plasma as an antifungal therapy, Applied Physics Letters 98 (2011) 021501

${ }^{253}$ H.Y. Wu, P. Sun, H.Q. Feng, H.X. Zhou, R.X. Wang, Y.D. Liang, J.F. Lu, W.D. Zhu, J. Zhang, J. Fang, Reactive Oxygen Species in a Non-thermal Plasma Microjet and Water System: Generation, Conversion, and Contributions to Bacteria Inactivation-An Analysis by Electron Spin Resonance Spectroscopy, Plasma Processes and Polymers 9 (2012) 417-424.

${ }^{254}$ H. Jablonowski, R. Bussiahn, M.U. Hammer, K.D. Weltmann, T. von Woedtke, S. Reuter, Impact of plasma jet vacuum ultraviolet radiation on reactive oxygen species generation in bio-relevant liquids, Physics of Plasmas 22 (2015) 122008

${ }^{255}$ H. Uchiyama, K. Ishikawa, Q.L. Zhao, G. Andocs, N. Nojima, K. Takeda, M.C. Krishna, T. Ishijima, Y. Matsuya, M. Hori, K. Noguchi, T. Kondo, Free radical generation by non-equilibrium atmospheric pressure plasma in alcohol-water mixtures: an EPR-spin trapping study, Journal of Physics D-Applied Physics 51 (2018) 095202 ${ }^{256}$ A. Tani, Y. Ono, S. Fukui, S. Ikawa, K. Kitano, Free radicals induced in aqueous solution by non-contact atmospheric-pressure cold plasma, Applied Physics Letters 100 (2012) 254103

${ }^{257}$ H. Tresp, M.U. Hammer, J. Winter, K.D. Weltmann, S. Reuter, Quantitative detection of plasma-generated radicals in liquids by electron paramagnetic resonance spectroscopy, Journal of Physics D-Applied Physics 46 (2013) 435401

${ }^{258}$ Y. Gorbanev, A. Privat-Maldonado, and A. Bogaerts, Anal. Chem. 90 (2018) 13151.

259 Q. Guo, S.Y. Qian, R.P. Mason, J. Am. Soc. Mass Spectrom. 14 (2003) 862.

${ }^{260}$ B. Tuccio, R. Lauricella, L. Charles, Int. J. Mass Spectrom. 252 (2006) 47. 
261 J.-W. Lackmann, K. Wende, C. Verlackt, J. Golda, J. Volzke, F. Kogelheide, J. Held, S. Bekeschus, A. Bogaerts, V. Schulz-von der Gathen, K. Stapelmann, Sci. Rep. 8 (2018) 7736.

262 K. Wende, P. Williams, J. Dalluge, W. Van Gaens, H. Aboubakr, J. Bischof, T. von Woedtke, S.M. Goyal, K.-D. Weltmann, A. Bogaerts, K. Masur, P.J. Bruggeman, Biointerphases 10 (2015) 029518.

263 P. Lukes, E. Dolezalova, I. Sisrova, M. Clupek, Plasma Sources Sci. Technol. 23 (2014) 015019.

264 B. Tarabova, P. Lukes, M. Janda, K. Hensel, L. Sikurova, Z. Machala, Plasma Processes Polym. 15 (2018) 1800030.

265 M.M. Hefny, C. Pattyn, P. Lukes, J. Benedikt, J. Phys. D: Appl. Phys. 49 (2016) 404002.

${ }^{266}$ L. Zoia, D.S Argyropoulos, Eur. J. Mass Spectrom. 16 (2010) 175. 